\title{
Article \\ On the Use of Perforated Sound Absorption Systems for Variable Acoustics Room Design
}

\author{
Andreia Pereira 1,*, Anna Gaspar ${ }^{1}$, Luís Godinho ${ }^{1}$, Paulo Amado Mendes ${ }^{1}$, Diogo Mateus ${ }^{1}$ (D), Jesus Carbajo ${ }^{2}$, \\ Jaime Ramis ${ }^{2}$ and Pedro Poveda ${ }^{2}$
}

1 Department of Civil Engineering, ISISE, University of Coimbra, 3030-788 Coimbra, Portugal; uc2016202135@student.uc.pt (A.G.); lgodinho@dec.uc.pt (L.G.); pamendes@dec.uc.pt (P.A.M.); diogo@dec.uc.pt (D.M.)

2 System Engineering and Signal Theory, Department of Physics, University of Alicante, 03690 San Vicente del Raspeig, Spain; jesus.carbajo@ua.es (J.C.); jramis@ua.es (J.R.); pedro.poveda@ua.es (P.P.)

* Correspondence: apereira@dec.uc.pt

Citation: Pereira, A.; Gaspar, A.; Godinho, L.; Amado Mendes, P.; Mateus, D.; Carbajo, J.; Ramis, J.; Poveda, P. On the Use of Perforated Sound Absorption Systems for Variable Acoustics Room Design. Buildings 2021, 11, 543. https:// doi.org/10.3390/buildings11110543

Academic Editor: Cinzia Buratti

Received: 7 October 2021

Accepted: 4 November 2021

Published: 15 November 2021

Publisher's Note: MDPI stays neutral with regard to jurisdictional claims in published maps and institutional affiliations.

Copyright: (c) 2021 by the authors. Licensee MDPI, Basel, Switzerland. This article is an open access article distributed under the terms and conditions of the Creative Commons Attribution (CC BY) license (https:// creativecommons.org/licenses/by/ $4.0 /)$.

\begin{abstract}
An important challenge for acoustic engineers in room acoustics design is related to the acoustic performance of multi-purpose auditoriums, which are typically designed to suit several performance requirements. With this intent, the analysis of several scenarios is usually performed individually, and then an acceptable solution, that may be adapted to several situations, is selected. One way of providing a more appropriate acoustic performance for each function of the auditorium is using variable sound absorption techniques to control reverberation and other relevant acoustic phenomena associated to sound perception. In this paper, the acoustic behavior of a perforated system that may be suitable for achieving a variable acoustic solution for room acoustic design is addressed. In the design of a cost-effective solution, the surface appearance is kept unchanged, while variable acoustic behavior is achieved either by closing the holes in the back face of the perforated panel or by placing a porous material in varying positions inside the backing cavity, thus accomplishing different acoustic requirements within a multipurpose auditorium. An analytical approach, based on the transfer matrix method is employed for preliminary acoustic sound absorption assessment provided by the system and to develop optimized solutions. Diffuse sound absorption is then computed and used to simulate, by the ray-tracing method, the acoustic behavior of a multipurpose auditorium to demonstrate efficient acoustic performance for different types of use.
\end{abstract}

Keywords: room acoustics; sound absorption; analytical approach; ray tracing; perforated sound absorbent systems; variable acoustics design

\section{Introduction}

Most of the existing auditoriums of many cities have been designed to accommodate one type of use, while in common practice, these are used for different and complementary purposes. In the last years, increased attention has been given to the design of multipurpose halls in order to be more efficient by accommodating more than one acoustic type of performance [1].

One way of providing a more appropriate acoustic performance for each function of the auditorium is using variable acoustics techniques to control reverberation time and other relevant acoustic phenomena. These solutions can modify the acoustic environment either through the implementation of electroacoustic systems (active variable acoustics) or through architectural changes (passive variable acoustics).

Active variable acoustics normally make use of an electronic control system to enhance the room acoustic response by capturing the indoor sound field, using directional microphones and then using sophisticated digital signal processing technology to customize the reproduced sound $[2,3]$. 
Passive variable acoustic strategies may include changing the volume of the space or varying acoustic absorption/scattering of the surfaces, allowing to reduce or increase the reverberation time, control of the direction of the early energy and other acoustic parameters, such as clarity and definition. To obtain an effective change in the acoustic properties, a substantial absorption variation is required [1]. Examples of solutions that can modify sound absorption in an environment are the use of retractable curtains, hinged panels, adjustable audience seats or movable reflectors [4,5]. A concept consisting of the use of articulated panels, where one side has an absorbent material, being exposed when such space is used for theatre, while the other face has a reflective surface, being exposed when the auditorium changes for a musical concert [6-8], is widely used, but it requires some significant modifications in the architecture of the room. Most of the existing solutions implemented in auditoriums in the last years are manually controlled; however, with the development of electromechanical and control systems [9] at more affordable costs, other possibilities for the implementation of such systems have been arising [3]. In the present work, a passive variable acoustic concept is explored, having in mind the possibility of automatization, for its implementation in multipurpose halls.

In terms of acoustical requirements for different purposes, such as conferences or concerts, the same space should fulfil considerable different needs. Even when designing variable acoustic solutions just for one type of use, it may not cover all requirements defined for that specific purpose. For instance, concert use refers to different types of music [6]. In the literature on room acoustics, information about classical, chamber and symphonic music is easily found, but there are other types of presentations, such as popular music (rock, jazz and country), which differ due to the type of musical instruments and frequency balance, consequently requiring different acoustical characteristics [10,11].

During the design of a room, the first parameter to be analyzed is the reverberation time, being possible to change this metric by varying the absorption inside the auditorium. This can be accomplished by using systems composed of combinations of porous or fibrous materials that, through their properties (such as porosity, fiber length, density or material thickness), allow to enhance absorption in the higher frequencies, volume absorbers [12,13], such as air cavities, and panel absorbers. These last ones may be used as lining panels separating porous/fibrous material and air gaps from the auditorium. If this lining is composed of multiple perforated panels, the sound absorption performance of these systems depends also on the properties of each perforated panel, such as perforation type, diameter, central distance and perforation ratio [14]. By modifying some of these parameters, it is possible to achieve a range of sound absorption performance of a variable acoustic system.

In this paper, a passive variable acoustics concept, based on the ideas described, is developed and its acoustic performance is analyzed. With this aim, sound absorption systems that may be suitable for achieving a variable acoustic solution, for room acoustic design, are addressed, making use of perforated panels, porous materials and air gaps of varying thickness. The concept herein proposed allows maintaining the architecture of the room while the acoustic environment is modified. The analysis is performed using a mathematical model based on the transfer matrix method to obtain the sound absorption coefficient for normal incidence, thereby evaluating different perforated panels with circular perforations. The concept is then applied in a conceptual multipurpose auditorium, where the acoustic performance is studied for different types of use by developing a model based on the ray-tracing method [15]. Several acoustic parameters are calculated and compared with different requirements, established for different types of use.

\section{Concept Description}

The acoustic system herein developed makes use of a perforated panel facing the auditorium and an air gap with a fixed thickness, containing an absorbing material (e.g., mineral wool), whose position may vary. Figure 1 displays the configurations that may be applied depending on the space and acoustic requirements. Behind this perforated 
panel, a movable panel (schematically represented in the figure by changing the color of the panel) will allow to close the holes and change the acoustic properties to approach a reflective surface (although allowing some diffusion in the higher frequencies). The reflective surface may be achieved using a back perforated rigid panel, not aligned with the front one (represented in Figure 1 with yellow color). This configuration is indicated in Figure 1 as " $R$ ". When the movable back panel is aligned with the perforated front panel, absorption provided by the perforated solution is attained (configurations A, B and $\mathrm{C}$ in Figure 1). Tuning absorption is still possible by changing the position of the mineral wool inside the air gap. In configuration A, the mineral wool is placed near the perforated panel, configuration B displays the mineral wool positioned in the center of the air gap, and configuration $C$ refers to the mineral wool placed near the back surface.

As it will be shown later, these configurations can be designed so as the two extreme acoustic types of use (speech and classical music) can be provided with sound quality, but it may also allow fulfilling intermediate acoustic requirements by appropriately configuring the panel system (changing the position of the mineral wool panel or opening/closing the holes of the perforated panel). This tuning feature can be achieved by using an automatized system as it will be described next. It is also important to bear in mind that, although from the acoustic point of view it is possible to modify the space, from the architectural point of view, the chosen solution does not change the aesthetics of the room, which may be an advantage of such a system for practical use.

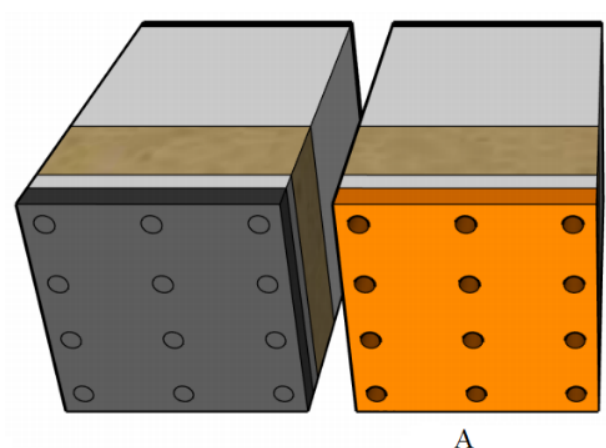

A

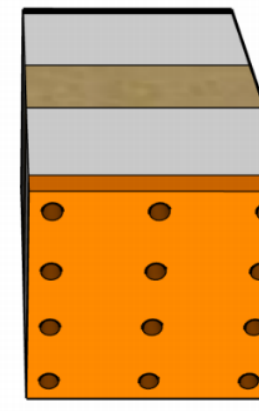

B

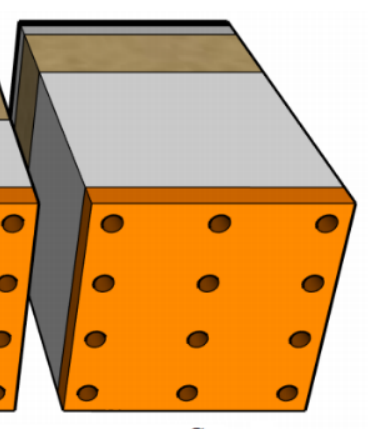

$\mathrm{C}$

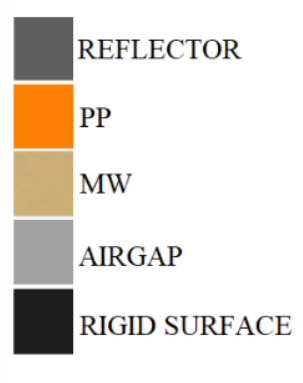

Figure 1. Possible configurations of the variable acoustic solution (acronyms: PP—perforated panel; MW—mineral wool; $\mathrm{R}$-reflective configuration); (A) configuration with mineral wool placed near the perforated panel; (B) configuration with mineral wool placed in the center of the air gap; (C) configuration with mineral wool placed near the back surface.

The proposed acoustic solution can be easily automated through the use of an electromechanical system [16-18], allowing the different configurations to be activated. Using lateral linear bearing rails and coupling the internal absorbing panel to a stepper motor using a trapezoidal thread spindle, the configuration of each element can be modified to adapt its acoustic behavior to the requirements of the room in different situations. Additionally, by incorporating a control system, each panel could be controlled remotely and independently. Note that in order to allow for mechanization of the system, a small air gap was left in the extreme positions of the absorbing material (see Figure 1).

\section{Sound Absorption Evaluation}

The approach used in this paper to evaluate the sound absorption of a variable acoustic conceptual system is based on the evaluation of the acoustic impedance of each layer (e.g., perforated panel, porous material or air gap) of the multilayer sound absorber. In the case of the perforated panel, the acoustic impedance of a single hole is used to obtain that of the whole panel by using its open area ratio, the panel being considered a set of short tubes of similar length to its thickness. It is also assumed that the wavelength of the sound that propagates is sufficiently large, compared with the dimensions of the tube (i.e., hole). The impedance of the panel includes terms due to the viscosity of air, radiation (from a hole in a baffle) and interaction between holes. On the other hand, an equivalent fluid is defined to 
describe the porous material whose skeleton is assumed to be rigid by means of its effective acoustic properties (i.e., complex characteristic impedance and wave number), and the air gaps being modeled by means of a purely reactance term.

An example arrangement of the absorber is shown in Figure 2. The system is considered to be locally reacting, assuming incidence of sound normal to the plane of the interface.

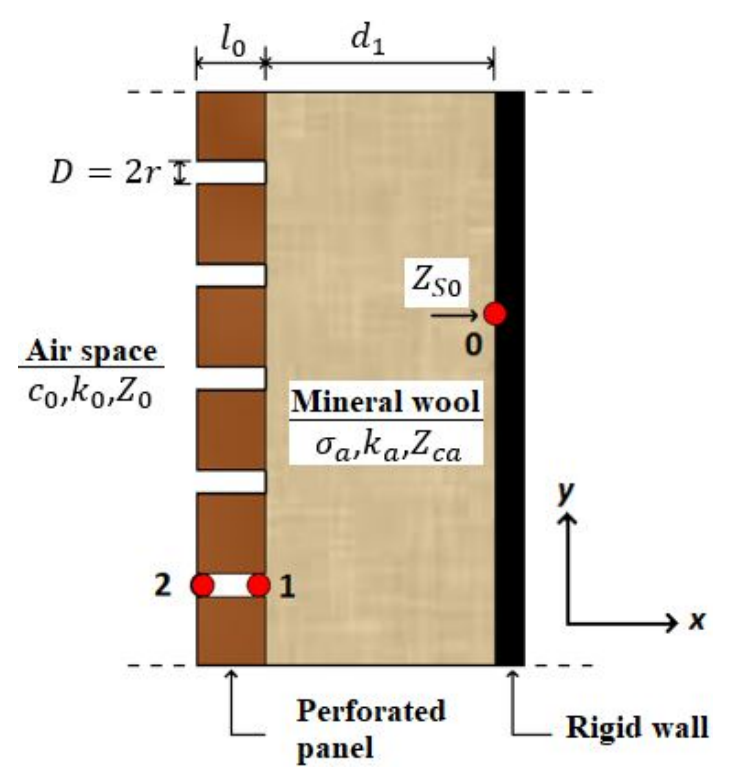

Figure 2. Configuration of an example perforated system.

For this case, at point 0 , the normal surface impedance is infinite $\left(Z_{s_{0}}=\infty\right)$, since it is considered as a rigid wall. The normal surface impedance at point 1 reads as follows:

$$
Z_{S_{1}}=-i Z_{c_{a}} \cot \left(k_{a} d_{1}\right)
$$

where $Z_{\mathcal{c}_{a}}$ is the characteristic impedance of the mineral wool, $k_{a}$ is its wavenumber, and $d_{1}$ is the thickness of this porous material. The corresponding values of such parameters may be obtained experimentally [19] by inversion from its physical properties [20] or using empirical predictions from regression analyses of measured sound absorption data [21]. A similar expression can be used in the case of an air gap of thickness $d_{1}$, the effective properties used in that case being those of air.

The surface impedance of the total system (point 2) along the normal direction can be obtained from the following:

$$
Z_{S_{2}}=Z_{s_{\text {panel }}}+Z_{S_{1}}
$$

where the acoustic transfer impedance of a perforated panel is given by the following:

$$
Z_{s_{\text {panel }}}=\frac{Z_{s_{\text {tube }}}}{\varepsilon}
$$

$\varepsilon$ being the perforation rate of the panel. According to Crandall [22], the impedance of one hole (tube) is the following:

$$
Z_{s_{\text {tube }}}=i \omega \rho_{0} l_{0}\left[1-\frac{2 J_{1}\left(k_{s} r\right)}{\left(k_{s} r\right) J_{0}\left(k_{s} r\right)}\right]^{-1}+\left[2 \sqrt{2 \omega \rho_{0} \eta}+\rho_{0} c_{0} \pi^{2}\left(\frac{2 r}{\lambda}\right)^{2}+i \omega \rho_{0} \delta\right]
$$

where $c_{0}$ is the air velocity, $\rho_{0}$ is the air density, $\omega$ is the angular frequency, $J_{0}$ is the thickness of the perforated panel, $r$ is the radius of the circular hole, $\eta$ is the coefficient of air viscosity, $\lambda$ is the wavelength, $J_{n}$ is the $n$th order of Bessel function, and $k_{s}=\sqrt{-i \rho_{0} / \eta}$ is the Stokes wave number. 
The second term on the right-hand side of Equation (4) is the end correction, which accounts for the interaction between the orifices via the following expression (see [14,22]):

$$
\delta=\frac{16 r}{3 \pi}\left(1-1.47 \sqrt{\varepsilon}+0.47 \sqrt{\varepsilon^{3}}\right)
$$

To allow the evaluation of generic systems with arbitrary layers, the transfer matrix method (TMM) [23] is used, where the acoustic impedance along the normal direction of an interface of a material is determined using the continuity of particle velocity (on both sides of the interface) and knowing the acoustic properties of the medium (characteristic impedance, $Z_{c}$, and the wavenumber or propagation constant, $k$ ). In this method, each layer is represented, using a generic transfer matrix that relates the sound pressure and particle velocity at the upstream $\left(M_{i}\right)$ and downstream $\left(M_{i}{ }^{\prime}\right)$ of the layer, allowing to establish the following relation:

$$
\left[\begin{array}{l}
p\left(M_{i}\right) \\
v\left(M_{i}\right)
\end{array}\right]=[T]\left[\begin{array}{l}
p\left(M_{i}^{\prime}\right) \\
v\left(M_{i}^{\prime}\right)
\end{array}\right]=\left[\begin{array}{ll}
t_{i, 11} & t_{i, 12} \\
t_{i, 21} & t_{i, 22}
\end{array}\right]\left[\begin{array}{l}
p\left(M_{i}^{\prime}\right) \\
v\left(M_{i}^{\prime}\right)
\end{array}\right]
$$

where $[T]_{i}$ is the transfer matrix corresponding to the $i$ th layer [24]. For a layer $i$, the following matrix can be established:

$$
[T]_{i}=\left[\begin{array}{cc}
\cos \left(k_{i} d_{i}\right) & i Z_{c, i} \sin \left(k_{i} d_{i}\right) \\
\frac{i}{Z_{c, i}} \sin \left(k_{i} d_{i}\right) & \cos \left(k_{i} d_{i}\right)
\end{array}\right]
$$

where $Z_{c, i}$ and $k_{i}$ are the complex characteristic impedance and the wave number in the layer, respectively. By multiplying the individual transfer matrices, the overall transfer matrix of the multilayered system can be obtained as follows:

$$
[T]_{M}=[T]_{1}[T]_{2} \ldots[T]_{N}=\left[\begin{array}{ll}
t_{11} & t_{12} \\
t_{21} & t_{22}
\end{array}\right]
$$

For layers corresponding to thin perforated panels, where the upstream and downstream particle velocities are assumed to be the same [25], the following matrix can be established:

$$
[T]_{p p}=\left[\begin{array}{cc}
1 & Z_{p p} \\
0 & 1
\end{array}\right]
$$

where $Z_{p p}$ is the acoustic transfer impedance of the perforated panel, which can be given by Equation (3).

The surface impedance of the whole absorber is then calculated as $Z_{s}=t_{11} / t_{21}$, and after calculating the surface impedance of the system, the sound absorption coefficient for a sound incidence angle $\theta$ to the normal direction of the surface (considering locally reactive systems) is given by the following:

$$
\alpha(\theta)=1-|R(\theta)|^{2}
$$

where $R(\theta)$ is the reflection coefficient that can be approximated in terms of the normal surface impedance $Z_{S}$ of the total system from the following:

$$
R(\theta)=\frac{Z_{s} \cos \theta-Z_{0}}{Z_{S} \cos \theta+Z_{0}}
$$

with $Z_{0}=\rho_{0} c_{0}$ being the acoustic impedance of the air.

To provide a validation of the response given by the TMM for some of the configurations to be analyzed, experiments were carried out in an impedance tube following the procedure described in the ISO 10534-2: 1998 [26]. A sample composed of a perforated panel $\left(l_{0}=12 \mathrm{~mm}, r=3 \mathrm{~mm}\right.$ and $\varepsilon=11.5 \%$, as in Figure 3(a1)), mineral wool (with 
density of $70 \mathrm{~kg} / \mathrm{m}^{3}$ and flow resistivity of $28,377 \mathrm{~Pa} \cdot \mathrm{s} \cdot \mathrm{m}^{-2}$, as in Figure 3(a2)) with $20 \mathrm{~mm}$ thickness, and an air gap with $68 \mathrm{~mm}$ thickness were used. The mineral wool was placed in two different positions: on the back of the perforated panel (see Figure 3(b1)) and next to the rigid surface (see Figure 3(b2)).

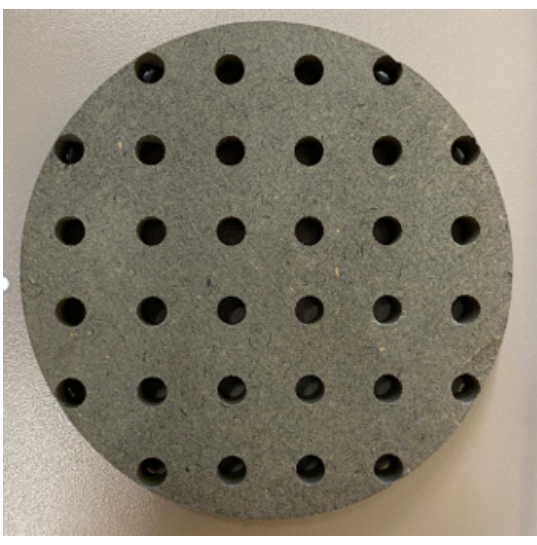

(a1)

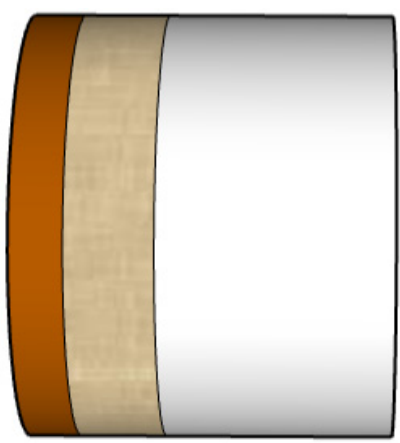

(b1)

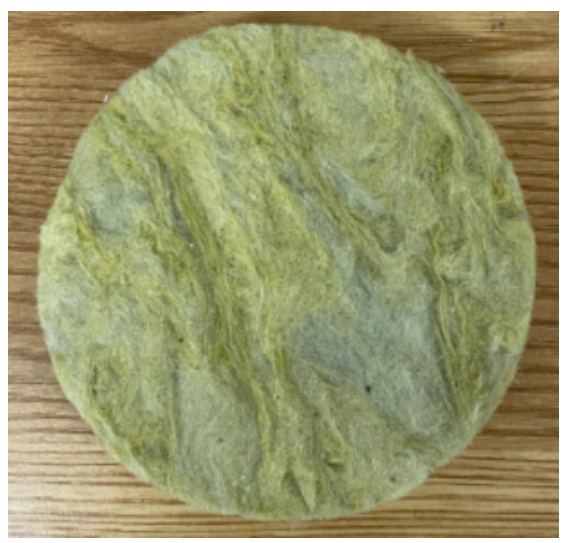

(a2)

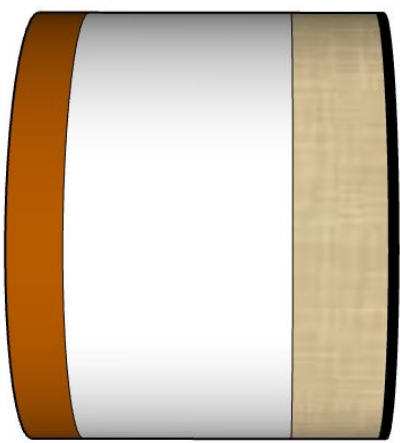

(b2)

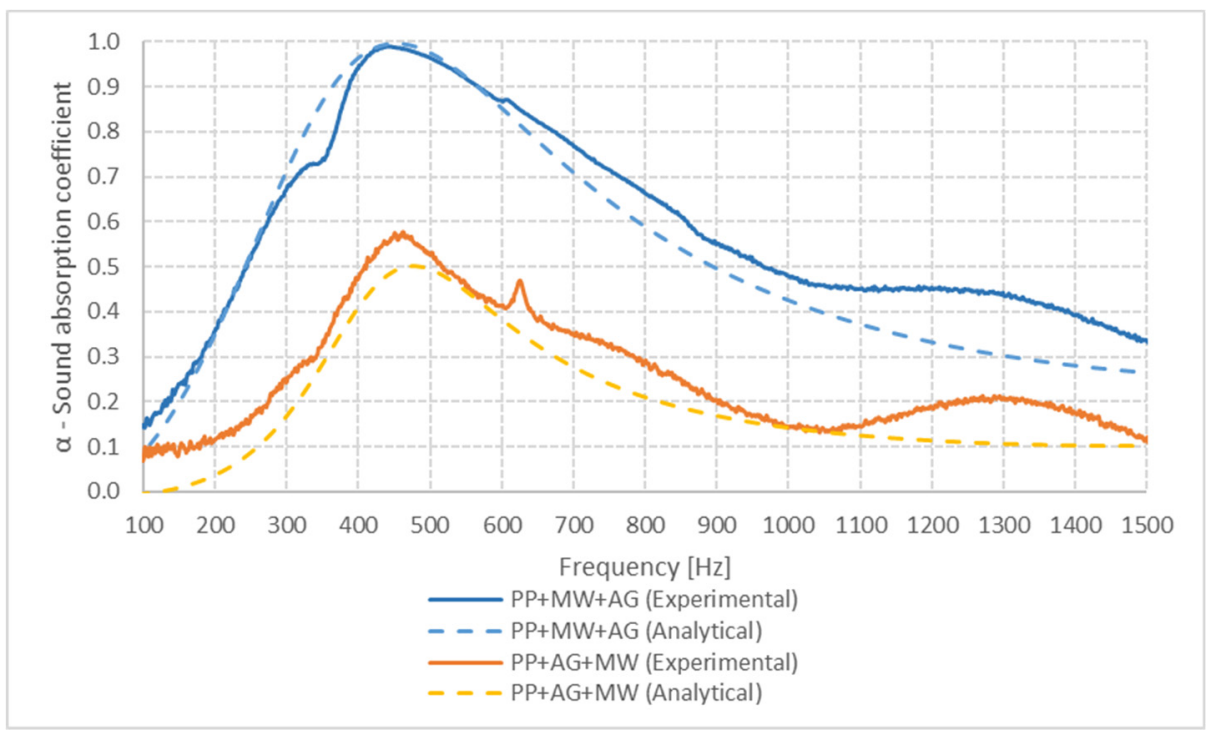

(c)

Figure 3. Comparison of the TMM and the experimental results, for two of the analyzed cases: (a) composition of samples: (a1) perforated panel; (a2) mineral wool; (b) configurations tested: (b1) $\mathrm{PP}+\mathrm{MW}+\mathrm{AG}$; (b2) $\mathrm{PP}+\mathrm{AG}+\mathrm{MW}$; (c) results calculated by the analytical approach and experimental data. 
The results evaluated by the analytical approach and the experimental tests for the two analyzed configurations are given in Figure 3c, where it is possible to verify that the analytical predictions are in good agreement with the experiments and allow to identify the peak of sound absorption and general acoustic behavior provided by both configurations. It is also interesting to note that when the mineral wool is on the back of the perforated panel (PP $+\mathrm{MW}+\mathrm{AG}$ ), increased absorption is attained, while when it is placed close to the rigid surface, a decrease in the sound absorption amplitude is found. This result indicates that it is, therefore, possible to change absorption amplitudes by varying the position of the mineral wool inside the air gap.

Finally, in order to obtain the diffuse sound absorption coefficient, the approach provided by [27] was followed. These tools are used in the next section to obtain the sound absorption provided by a solution designed to fulfil the acoustic requirements of a multipurpose auditorium.

\section{Auditorium Simulation}

\subsection{Model Description}

The conceptual auditorium used has a capacity for 409 seats, mean dimensions of $18.9(\mathrm{~m}) \times 16.9(\mathrm{~m}) \times 11.9(\mathrm{~m})$, and a total volume of $3779 \mathrm{~m}^{3}$. It is composed of the stage area, with a volume of $1448 \mathrm{~m}^{3}$, and an audience area, totaling to a volume of $2331 \mathrm{~m}^{3}$. The volume per seat is approximately $9 \mathrm{~m}^{3}$. Note that this auditorium does not correspond to an existing space. The geometry was prepared using SketchUp 3D design software and can be seen in Figure 4.
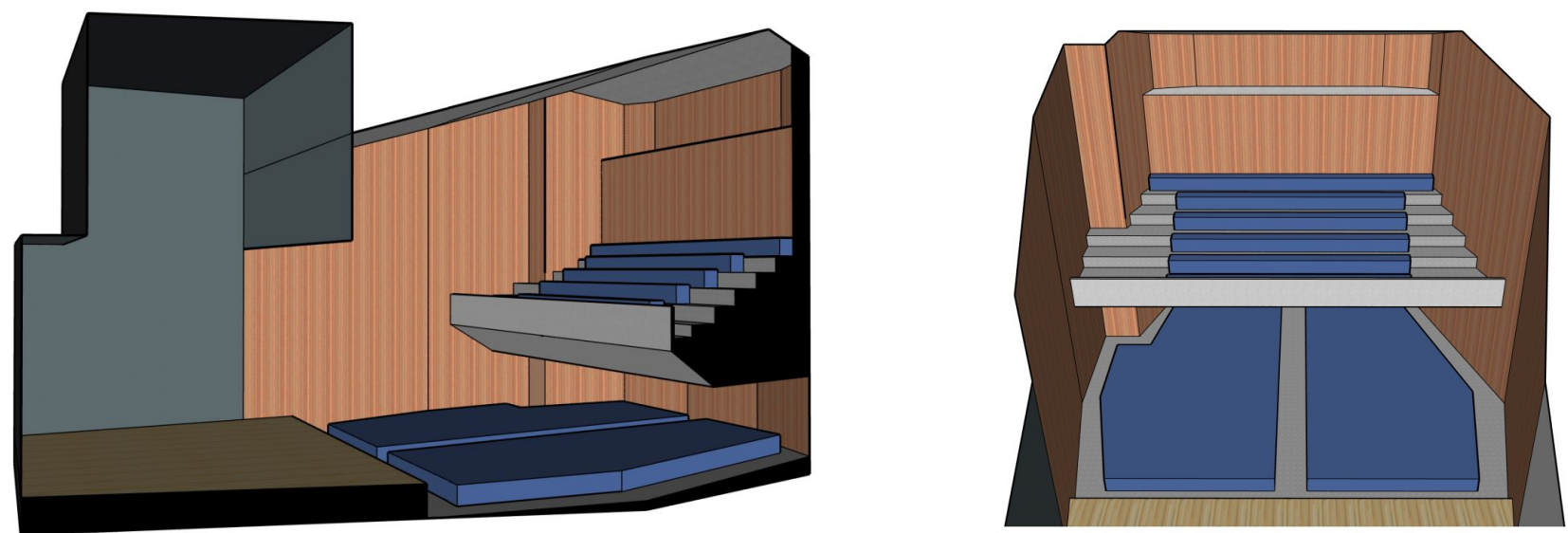

Figure 4. SketchUp 3D views of the geometrical model of the auditorium.

The simulations were performed using a ray tracing code developed in MATLAB, which used around 30,000 rays during the calculation and an impulse response (IR) length of $2 \mathrm{~s}$. This method uses a large number of particles (rays) emitted by an omnidirectional sound source. The rays travel through the room, losing energy in each reflection according to the absorption coefficient of the surfaces [28]. Using this computational method, it is possible to calculate several objective acoustic parameters, such as reverberation time (RT), sound pressure level (SPL), definition (D50), clarity (C80), speech transmission index (STI), and strength $(\mathrm{G})$. The SketchUp 3D modeling of the space is exported to the MATLAB environment to carry out the acoustic assessment in a complementary numerical tool.

For the acoustic simulation, Schroeder's frequency, regarded as the frequency between the zone of modal and statistical behavior, which can be expressed as $f_{s}=2000 \sqrt{T / V}$ [29], (with $T$ being the reverberation time and $V$ the volume of the space), should be evaluated. For the present case, and for the most unfavorable configuration, the value of this frequency is $31 \mathrm{~Hz}$. It is common, in practice, to considerer a value of four times the Schroeder frequency to define a reliable limit of the calculation using ray tracing. For the present case, this value corresponds to $125 \mathrm{~Hz}$, meaning that, below this frequency, some error may occur. Figure 5 displays the geometry of the acoustic model (built with 111 planes and 
a total surface area of $2008 \mathrm{~m}^{2}$ ) and the corresponding lining materials, where it is also possible to identify the position of the variable acoustic solution previously described in this work. This solution was positioned on the front wall (in relation to stage) and on the lateral walls aligning with the balcony zone.
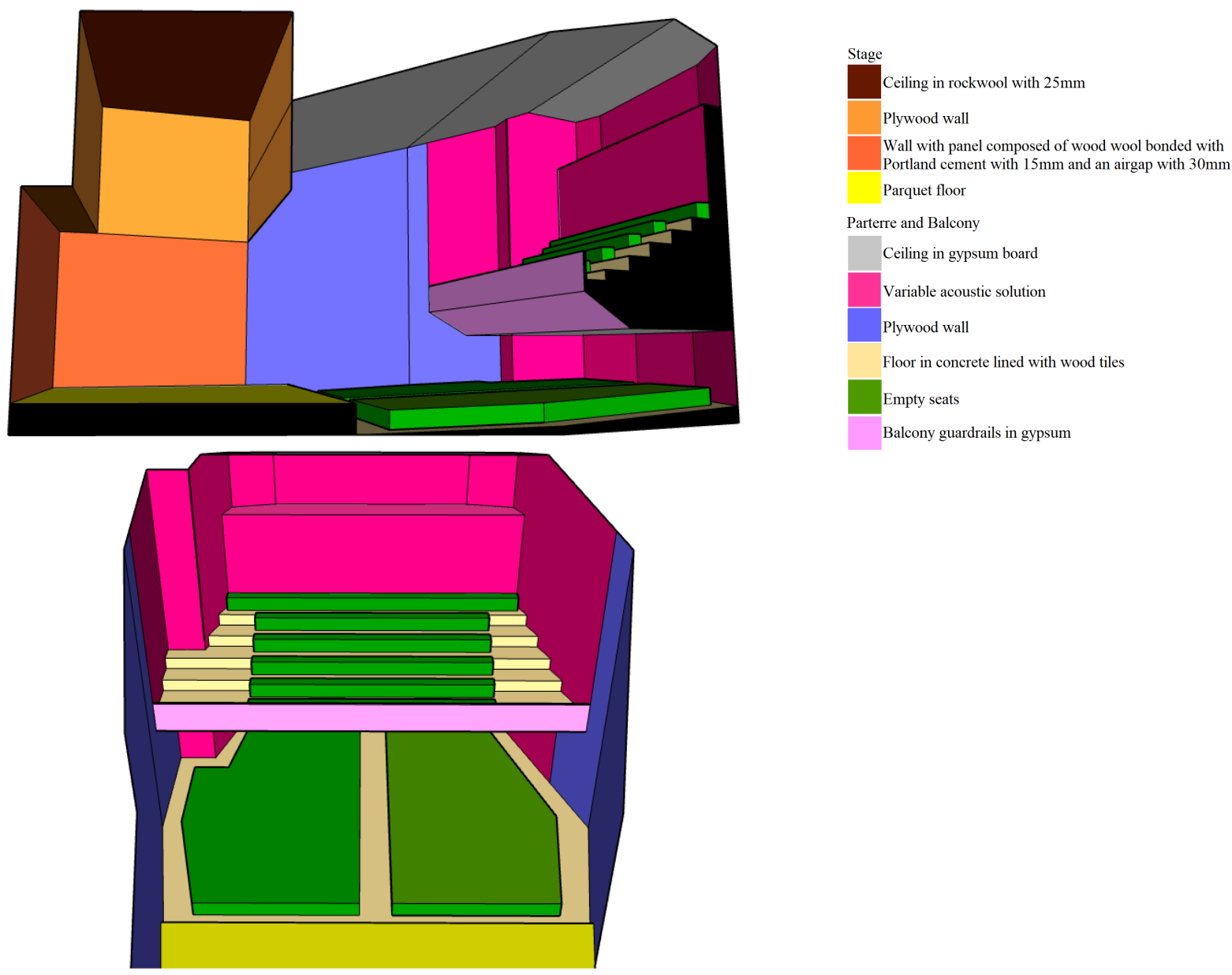

Figure 5. Geometry of the auditorium and distribution of the applied lining materials.

The variable acoustic solution employed in this auditorium (see Figure 1) was designed such that its two extreme types of use (speech and classic music) can be provided with enough sound quality for the above-described auditorium, but also to allow intermediate acoustic requirements. Tables 1 and 2 display the relevant properties of the perforated panel and mineral wool used for the analyzed system. Note that in the case of the perforated panel, the properties differ from those used in Section 3 because in order to fulfil the requirements for sound quality within the auditorium, it was necessary to adjust the corresponding perforation rate.

Table 1. Properties of perforated panel and porous material.

\begin{tabular}{ccccc}
\hline ID & Panels & Thickness $(\mathbf{m m})$ & $\begin{array}{c}\text { Diameter of the } \\
\text { Hole }(\mathbf{m m})\end{array}$ & $\begin{array}{c}\text { Perforation Rate } \\
\mathbf{( \% )}\end{array}$ \\
\hline PP & Perforated & 12 & 8 & 18 \\
\hline ID & Porous material & Thickness $(\mathrm{mm})$ & Density $\left(\mathrm{kg} / \mathrm{m}^{3}\right)$ & $\begin{array}{c}\text { Flow resistivity } \\
\text { Pa } \cdot \mathrm{s} \cdot \mathrm{m}^{-2}\end{array}$ \\
\hline MW & Mineral Wool & $40 \mathrm{~mm}$ & 70 & 28,377 \\
\hline
\end{tabular}


Table 2. Definition of the different layers for each system of the set of configurations.

\begin{tabular}{ccccc}
\hline Configuration & Layer 1 & Layer $\mathbf{2}$ & Layer 3 & Layer 4 \\
\hline $\mathrm{A}$ & $\mathrm{PP}$ & $\begin{array}{c}\text { Airgap } \\
\mathrm{d} 1=10 \mathrm{~mm}\end{array}$ & $\mathrm{MW}$ & $\begin{array}{c}\text { Airgap } \\
\mathrm{d} 1=100 \mathrm{~mm}\end{array}$ \\
\hline $\mathrm{B}$ & $\mathrm{PP}$ & $\begin{array}{c}\text { Airgap } \\
\mathrm{d} 1=55 \mathrm{~mm}\end{array}$ & $\mathrm{MW}$ & $\begin{array}{c}\text { Airgap } \\
\mathrm{d} 1=55 \mathrm{~mm}\end{array}$ \\
\hline $\mathrm{C}$ & $\mathrm{PP}$ & $\begin{array}{c}\text { Airgap } \\
\mathrm{d} 1=100 \mathrm{~mm}\end{array}$ & $\mathrm{MW}$ & $\begin{array}{c}\text { Airgap } \\
\mathrm{d} 1=10 \mathrm{~mm}\end{array}$ \\
\hline
\end{tabular}

The sound absorption and scattering coefficients used in the simulations for the materials applied on different surfaces are displayed in Table 3, as well as the relative area of each material. Except for the variable acoustic solution, all coefficients were obtained from several relevant references $[14,15,30,31]$. For the evaluation of sound absorption provided by the perforated configurations of the variable acoustic solution, the transfer matrix method was applied, and diffuse field conditions were then computed using the approach defined in [27]. Regarding the reflective configuration, sound absorption coefficients were those from experimental results obtained for similar existing commercial solutions.

Table 3. Sound absorption $(\alpha)$ and scattering (s) coefficients for each lining material, and corresponding surface areas.

\begin{tabular}{|c|c|c|c|c|c|c|c|c|c|c|}
\hline \multirow{2}{*}{ AuditoriumPart } & \multirow{2}{*}{ Materials } & \multirow{2}{*}{$\begin{array}{c}\text { Area } \\
\mathrm{m}^{2}\end{array}$} & \multirow{2}{*}{$\begin{array}{c}\text { Area } \\
\%\end{array}$} & \multirow{2}{*}{$\begin{array}{c}\text { Acoustic } \\
\text { Parameter * }\end{array}$} & \multicolumn{6}{|c|}{ Octave Bands [Hz] } \\
\hline & & & & & 125 & 250 & 500 & 1000 & 2000 & 4000 \\
\hline \multirow{4}{*}{ Stage } & Ceiling in rockwool with $25 \mathrm{~mm}$ & 105.2 & 5.2 & $\alpha$ & 0.25 & 0.60 & 0.65 & 0.95 & 0.95 & 0.95 \\
\hline & Plywood wall & 267.1 & 13.3 & $\alpha$ & 0.11 & 0.10 & 0.07 & 0.05 & 0.05 & 0.05 \\
\hline & $\begin{array}{l}\text { Wall with panel composed of wood } \\
\text { wool bonded with Portland cement } \\
\text { with } 15 \mathrm{~mm} \text { and an airgap with } 30 \mathrm{~mm}\end{array}$ & 182.4 & 9.1 & $\alpha$ & 0.10 & 0.15 & 0.40 & 0.75 & 0.45 & 0.55 \\
\hline & Parquet floor & 148.1 & 7.4 & $\alpha$ & 0.02 & 0.03 & 0.04 & 0.05 & 0.05 & 0.06 \\
\hline \multirow{14}{*}{$\begin{array}{l}\text { Parterre and } \\
\text { Balcony }\end{array}$} & Ceiling in gypsum board & 335.0 & 16.7 & $\alpha$ & 0.12 & 0.10 & 0.08 & 0.06 & 0.06 & 0.06 \\
\hline & Plywood wall & 223.8 & 11.1 & $\alpha$ & 0.11 & 0.10 & 0.07 & 0.05 & 0.05 & 0.05 \\
\hline & Floor in concrete lined with wood tiles & 144.5 & 7.2 & $\alpha$ & 0.02 & 0.04 & 0.05 & 0.04 & 0.10 & 0.05 \\
\hline & Empty chairs, low upholstered & 2718 & 135 & $\alpha$ & 0.25 & 0.35 & 0.47 & 0.51 & 0.49 & 0.45 \\
\hline & Empty chairs, low upnoisterea & 271.8 & 13.5 & $\mathrm{~s}$ & 0.20 & 0.30 & 0.40 & 0.50 & 0.60 & 0.70 \\
\hline & Balcony guardrails in gypsum & 73.7 & 3.7 & $\alpha$ & 0.12 & 0.10 & 0.08 & 0.06 & 0.06 & 0.06 \\
\hline & Variable A coustic Configuration A & & & $\alpha$ & 0.88 & 0.99 & 0.99 & 0.92 & 0.48 & 0.24 \\
\hline & variable Acoustic Contiguration A & & & $\mathrm{s}$ & 0.12 & 0.13 & 0.14 & 0.15 & 0.16 & 0.17 \\
\hline & Variable A couctic Configuration $B$ & & & $\alpha$ & 0.63 & 0.92 & 0.90 & 0.55 & 0.37 & 0.27 \\
\hline & variabie Acoustic Connguration D & & & $\mathrm{s}$ & 0.12 & 0.13 & 0.14 & 0.15 & 0.16 & 0.17 \\
\hline & Variable Acoustic Confiouration $C$ & & & $\alpha$ & 0.20 & 0.42 & 0.49 & 0.53 & 0.48 & 0.24 \\
\hline & variable Acoustic Configuration C & & & $\mathrm{s}$ & 0.12 & 0.13 & 0.14 & 0.15 & 0.16 & 0.17 \\
\hline & Variable Acoustic Configuration & & & $\alpha$ & 0.20 & 0.10 & 0.10 & 0.10 & 0.15 & 0.20 \\
\hline & Reflector & & & $\mathrm{s}$ & 0.12 & 0.13 & 0.14 & 0.15 & 0.16 & 0.17 \\
\hline
\end{tabular}

* By default, scattering coefficients not shown are assumed to be 0.10 .

For the acoustic simulations, 56 numerical receivers were placed in the audience seats area, grouped in 5 zones ( $\mathrm{A}$ and $\mathrm{B}$ situated in the parterre and $\mathrm{C}, \mathrm{D}$ and $\mathrm{E}$ in the balcony area), and an omnidirectional source, $\mathrm{A} 0$, was placed centered at $1.5 \mathrm{~m}$ from the front of the stage. The arrangement of the receivers and sound source are displayed in Figure 6 . The arrangement of the receivers by zones was employed to assist in the data analysis and enable a better understanding of the influence of this spatial distribution on the acoustic parameters. 

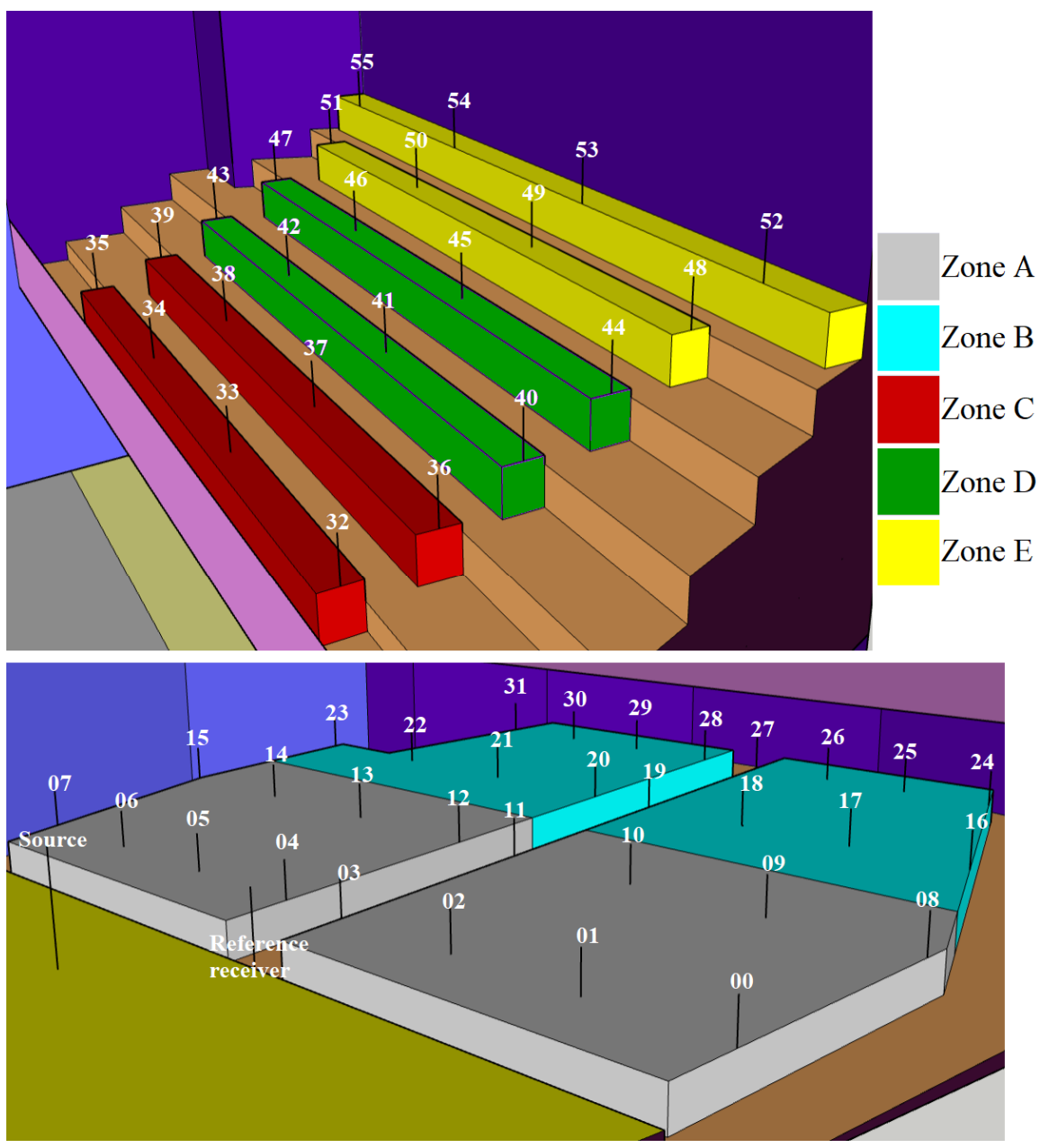

Figure 6. Position of sound source (situated on the stage), numerical receivers placed on the balcony (top figure) and on the parterre (bottom figure) and identification of the several receiver zones.

\subsection{Results}

\subsubsection{Preliminary Evaluation}

Since the reverberation time is initially used in a preliminary acoustic evaluation of a closed space, it is a fundamental indicator regarding the type of space. For the case of speech use, low reverberation times are required to have a better intelligibility of words, whereas for environments intended for music, higher values are recommended since it is necessary to create more "live" environments with greater sound diffusion [1].

Several published works indicate acoustic requirements for the reverberation time depending on the use of the closed space. For example, according to the Portuguese Acoustic Code for Buildings RRAE [32], in its article 10. ${ }^{\circ}$-A, the average reverberation time in the frequency bands of $500 \mathrm{~Hz}, 1000 \mathrm{~Hz}$ and $2000 \mathrm{~Hz}$, evaluated with the room furnished but without an audience, and assuming a use for speech purposes, should be less than or equal to that obtained by the following expression:

$$
T=0.32+0.17 \log (V) \text { for } V<9000 \mathrm{~m}^{3}
$$

with $V$ being the volume for the space in cubic meters.

For the present case study, this average reverberation time should be less than or equal to $0.9 \mathrm{~s}$. Regarding music and speech uses, Arau [33] suggests requirements for the reverberation time depending on the type of use and the volume of the space. The standard NS 8178 [34] is also an interesting reference to evaluate the specific case of music rooms. This standard provides a reference for the average reverberation time for performance 
rooms, as a function of this volume, according to three different types of music classified as amplified music, powerful acoustic music and weak acoustic music. For the analyzed performance room, with a volume of $3779 \mathrm{~m}^{3}$, the average recommended reverberation times are displayed in Table 4, according to these references.

Table 4. Recommended reverberation times (mid-frequency octave bands: $500 \mathrm{~Hz}$ and $1000 \mathrm{~Hz}$ ) suggested by Arau [33] and by standard NS 8178 [34], according to the type of use.

\begin{tabular}{|c|c|c|c|}
\hline Type of Use & Reverberation Time & Recommended Value (s) & Reference \\
\hline \multirow{2}{*}{ Theatre } & Tmax & 1.3 & \multirow{2}{*}{ Arau [33] } \\
\hline & Tmin & 0.8 & \\
\hline \multirow{2}{*}{ Opera } & Tmax & 1.5 & \multirow{2}{*}{ Arau [33] } \\
\hline & Tmin & 1.1 & \\
\hline \multirow{2}{*}{ Chamber music } & Tmax & 1.5 & \multirow{2}{*}{ Arau [33] } \\
\hline & Tmin & 1.3 & \\
\hline Concerts & Tmax & 1.8 & Arau [33] \\
\hline $\begin{array}{c}\text { Acoustic powerful } \\
\text { music }\end{array}$ & Tmin & 1.5 & Standard NS 8178 [34] \\
\hline \multirow{2}{*}{ Acoustic quiet music } & Tmax & 2.2 & \multirow{2}{*}{ Standard NS 8178 [34] } \\
\hline & Tmin & 1.8 & \\
\hline \multirow{2}{*}{ Amplified music } & Tmax & 1.0 & \multirow{2}{*}{ Standard NS 8178 [34] } \\
\hline & Tmin & 0.8 & \\
\hline
\end{tabular}

Figure 7 shows the average reverberation times obtained from the values registered at all receiver positions, for four possible variable acoustic perforated system configurations (configurations R, A, B and C). It is possible to verify that, except for the octave band of $4000 \mathrm{~Hz}$, there is a significant variation in the reverberation time of the auditorium between the two extreme configurations (configuration $\mathrm{R}$ and configuration $\mathrm{A}$ ). The remaining configurations allow the reverberation to fall in intermediate values.

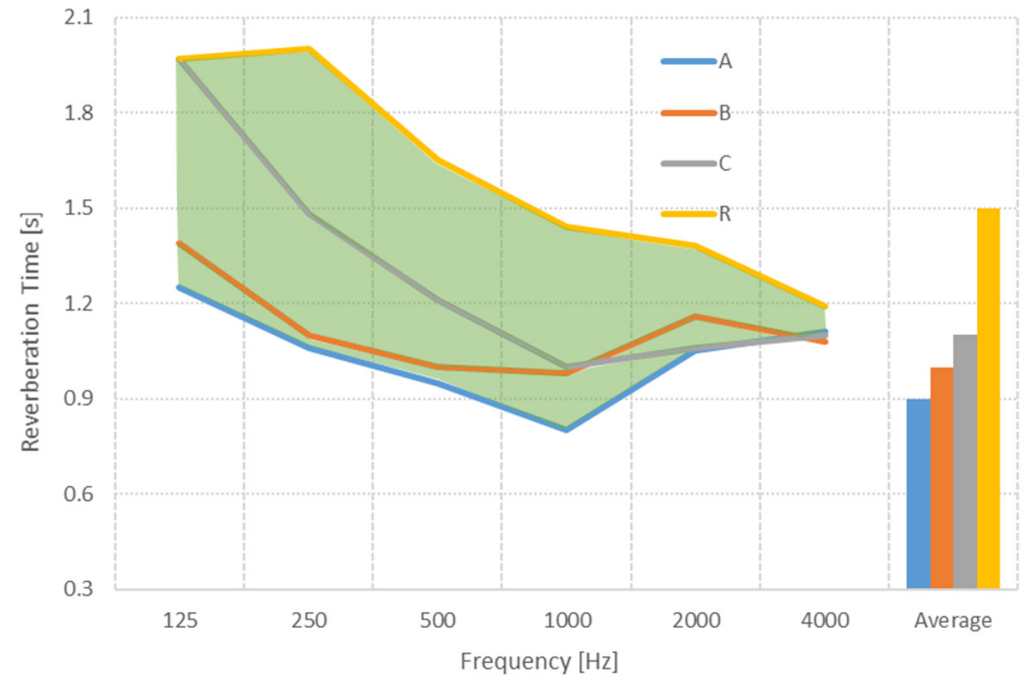

Figure 7. Average reverberation time (RT) in the auditorium for different octave bands obtained for the variable acoustic perforated systems analyzed (configurations R, A, B and C).

The differences among these solutions are also studied in terms of just accepted noticeable difference (JND) [35], which indicates the perceptible variation achieved with the variable acoustic solution. Higher values of JND indicate that the variable acoustic solution will allow to significantly modify the sound quality of space. For the reverberation time parameter, the differences in the results are calculated concerning the reflective configuration (configuration $\mathrm{R}$ ) and are then quantified in terms of the JND, according to 
the reference value defined in the ISO 3382-1-2009 [35] (JND of 5\%). Figure 8 shows the octave band results and also the average at frequency bands of $500 \mathrm{~Hz}$ and $1000 \mathrm{~Hz}$.

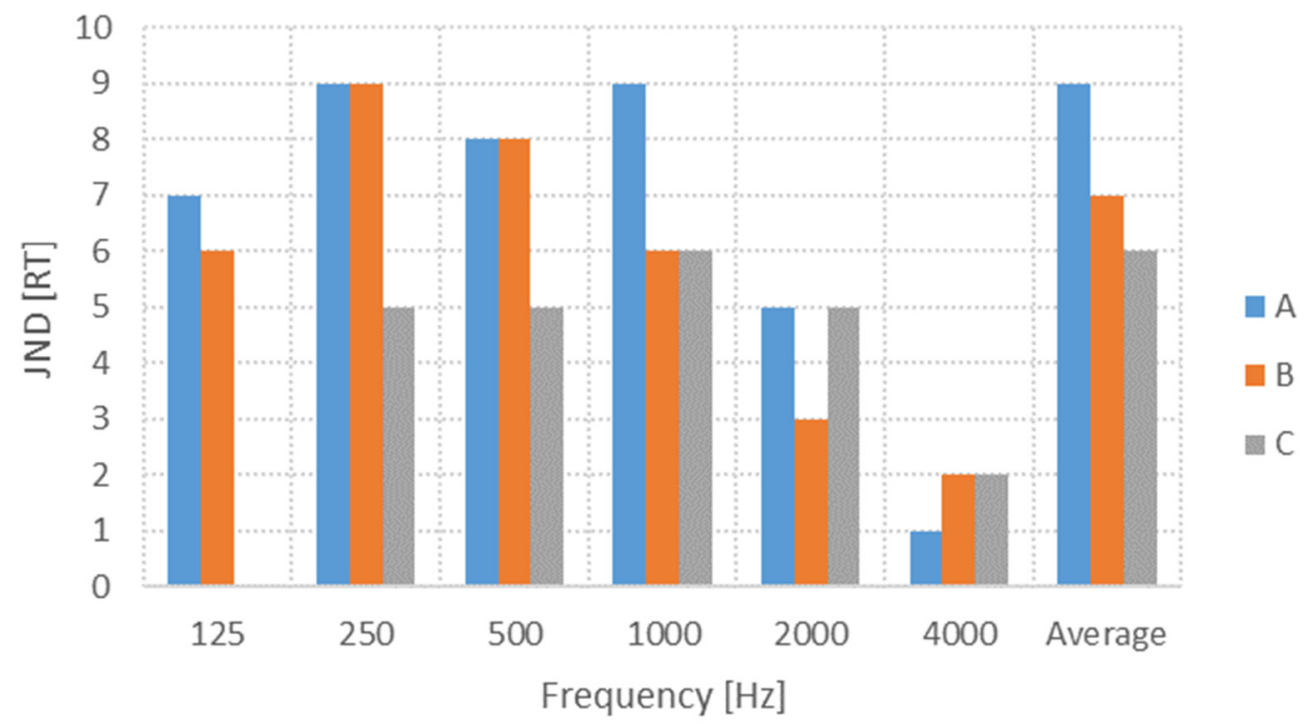

Figure 8. JND for reverberation time (RT) in the auditorium, for the studied variable acoustic configurations (configurations A, B and C).

From the previous analysis, it is possible to verify that the greater JND values are found for configuration A for all frequency bands, varying between 1 JND and 9 JND. Configuration B follows, displaying lower JND values in octave bands, although always greater than 2. The configuration with lower values of JND is configuration C. Looking at the average value, the JND values of the three configurations, in comparison with the reflective one, are quite expressive, ranging from 6 to 9 .

Comparing the average reverberation times with the reference ones (see Table 4), configuration A would be adequate for speech use or amplified music, configuration R for acoustic loud music, and configuration $C$ could be applied for opera music, while for quiet music, the auditorium would not provide good sound quality (higher reverberation times are required). The extreme configurations are further discussed regarding other relevant acoustic parameters.

\subsubsection{Speech Assessment}

\section{Reverberation Time}

Using the most absorbent position of the variable solution (configuration A), the average reverberation time of the auditorium, obtained for the unoccupied auditorium, from the values in the frequency bands of $500 \mathrm{~Hz}, 1000 \mathrm{~Hz}$ and $2000 \mathrm{~Hz}$ is $0.9 \mathrm{~s}$, which complies with the requirement imposed by Portuguese Regulation, Decree-Law No. 96/2008 (RRAE) [32], applied when spaces are used for speech purposes.

Figure 9a plots the reverberation times obtained by zones (according to the distribution illustrated in Figure 6), allowing to evaluate the spatial distribution of this parameter. From the analysis of this figure, we conclude that when using the variable acoustic solution in the maximum absorption position, the reverberation time is uniform (in the frequency range) through the space in the various areas of the auditorium. From the analysis of Figure $9 \mathrm{~b}$ displaying the average JND $(500 \mathrm{~Hz}, 1000 \mathrm{~Hz}$ and $2000 \mathrm{~Hz})$ by zones concerning the reflective configuration, a difference of 1 JND among zones can be found. 


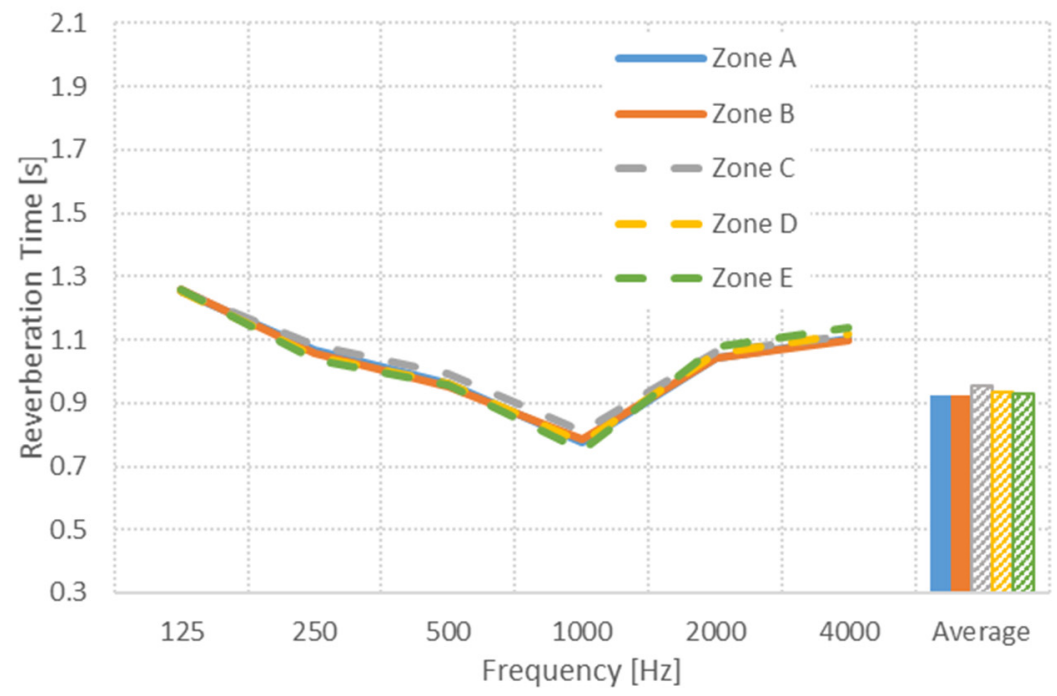

(a)

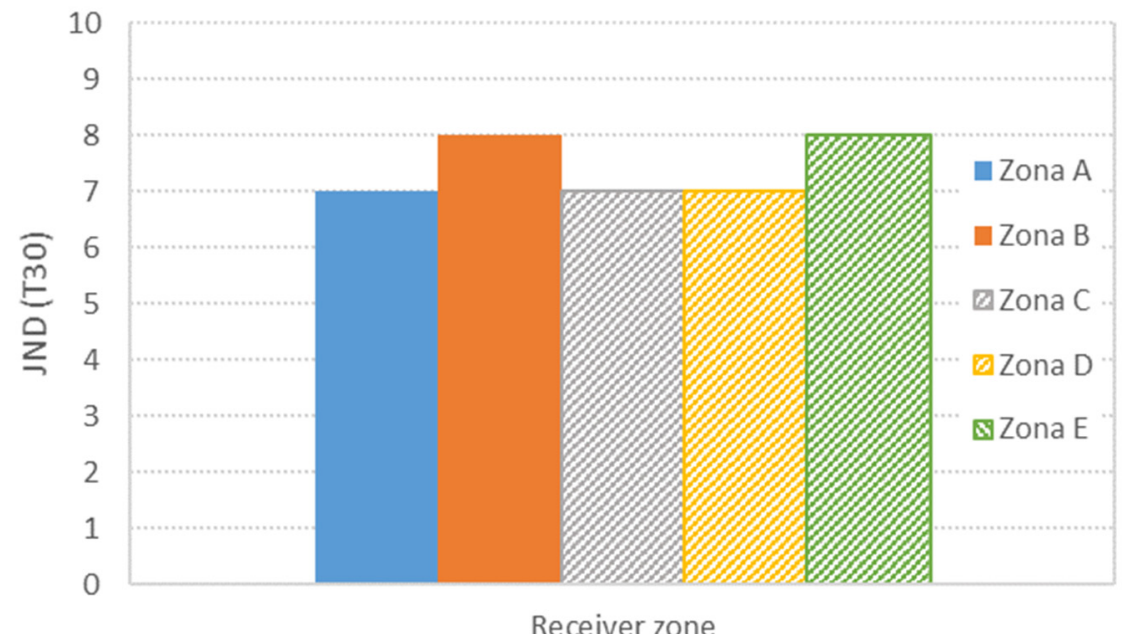

(b)

Figure 9. Reverberation time (a) and JND (b) obtained for the auditorium, when the variable acoustic solution provides maximum absorption, by zones (configuration A).

Sound Pressure Level

The equivalent sound pressure level was evaluated in decibel $(\mathrm{dB})$ as the result of the integration of the pressure levels in the frequency domain to characterize, as a single value, the sound pressure level along the space.

Figure 10 shows the equivalent sound pressure level values at each receiver position when the most absorbent configuration is adopted (configuration A).

Table 5 shows the spatial variation of the difference between the average sound pressure level obtained in each line of receivers concerning a specific point that corresponds to a receiver placed near the stage (reference receiver) $(\Delta \mathrm{L})$. In what concerns the parterre places, the lines of receivers located below the balcony lead to a greater difference in relation to the lines of receivers located near the stage, as it is also a region with more sound absorption when compared to other receiver positions. As for the balcony, there is some uniformity in the values of the variation of the sound pressure level, indicating a good distribution of the reflective and absorbent surfaces. To be perceptible to the human ear, $1 \mathrm{~dB}$ of variation in sound pressure levels would be acceptable; however, for higher values than $5 \mathrm{~dB}$, there is a clear change, which could lead to the complaints of users [30]. In the situation analyzed, only in receivers placed at the front of the parterre, there is a difference concerning the other seat positions, although the maximum difference (located at the last 
seats of the balcony) is less than $5 \mathrm{~dB}$, which indicates a good spatial distribution in sound pressure levels.

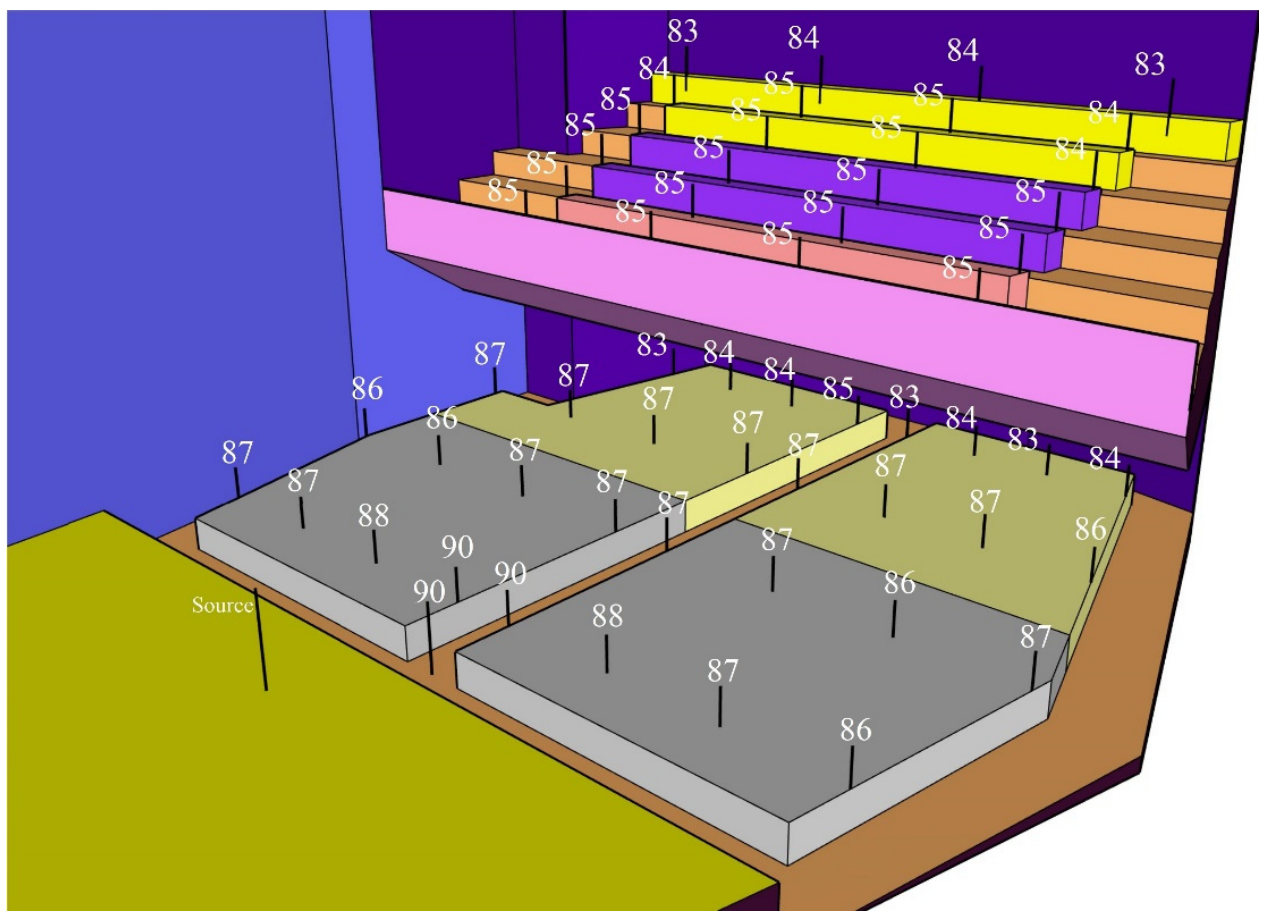

Figure 10. Map of the equivalent sound pressure levels in $\mathrm{dB}$, for the variable acoustic configuration which provides maximum sound absorption (suitable for oratory/speech use) (configuration A).

Table 5. Differences between sound pressure levels registered close to the source and that obtained at a receivers' line, for oratory/speech use $(\Delta \mathrm{L})$.

\begin{tabular}{ccccccccccc}
\hline & \multicolumn{3}{c}{ Parterre } & \multicolumn{5}{c}{ Balcony } \\
\hline $\begin{array}{c}\text { Distance between receiver } \\
\text { and reference receiver }(\mathrm{m})\end{array}$ & 2.9 & 5.2 & 8.2 & 11.4 & 8.1 & 9.2 & 10.2 & 11.4 & 12.5 & 13.3 \\
\hline$\Delta \mathrm{L}[\mathrm{dB}]$ & 2.0 & 3.7 & 5.5 & 6.1 & 5.5 & 5.2 & 5.7 & 5.7 & 5.8 & 6.4 \\
\hline
\end{tabular}

\section{Definition (D50)}

The definition (D50) is related to speech intelligibility and is measured in linear scale as the ratio between the energy contained in the time interval of the first reflections $(50 \mathrm{~ms}$ ) and the total energy of the impulse response according to the following expression:

$$
\mathrm{D} 50=\frac{\int_{0}^{50 \mathrm{~ms}} p^{2}(t) d t}{\int_{0}^{\infty} p^{2}(t) d t}
$$

The higher the value of D50, the better the listener capacity to distinguish each syllable, with values above $50 \%$ being considered acceptable [30]. This parameter is analyzed in the subsequent sub-section for the present case study.

Figure 11 shows the definition values (expressed in \%), which correspond to average values on several receiver positions, according to the above-defined zones. For the majority of the frequency bands, the values are situated above $50 \%$, varying from $48 \%$ to $74 \%$. Values slightly below $50 \%$ are registered in zone $\mathrm{D}(48 \%)$ for a frequency of $125 \mathrm{~Hz}$, and in zone $\mathrm{C}(49 \%)$, at frequency $4000 \mathrm{~Hz}$. The average definition value (at frequencies $500 \mathrm{~Hz}$ and $1000 \mathrm{~Hz}$ ) in the several zones is situated between $70 \%$ and $71 \%$, indicating a very good spatial distribution of this indicator. 


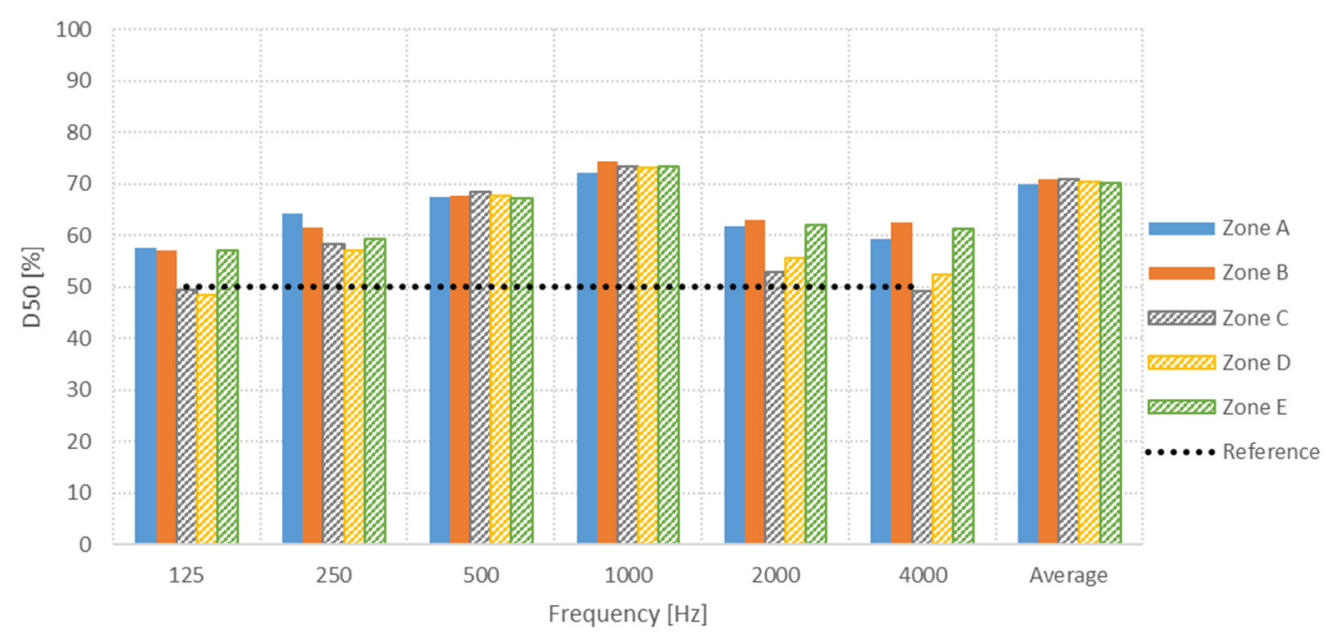

Figure 11. Definition (D50) obtained in the auditorium, when the variable acoustic solution provides maximum absorption (configuration A) for the different zones.

STI

The speech transmission index (STI) is a criterion used to quantify the measure of intelligibility of words, with values varying between 0 (null intelligibility) and 1 (optimum intelligibility) (see Table 6). The STI is measured by the speech signal modulation, starting from the condition that the speech signal is amplitude modulated; to have good intelligibility, one should have the minimum possible deformation [36].

Table 6. Relation between speech transmission quality and speech transmission index (STI).

\begin{tabular}{cccccc}
\hline STI & $<0.30$ & $0.30-0.45$ & $0.45-0.60$ & $0.60-0.75$ & $\geq 0.75$ \\
\hline Score & Bad & Poor & Fair & Good & Excellent \\
\hline
\end{tabular}

The analysis of this parameter is essential in the case of the use of the space for speech purposes to verify the measure of speech intelligibility in the sound environment. In the present case study, STI values range between 0.62 and 0.66 , as evidenced by the analysis of Figure 12, with the solution being characterized as good to oratory, according to Table 6 . It is also important to note that a good spatial distribution of this parameter was found.

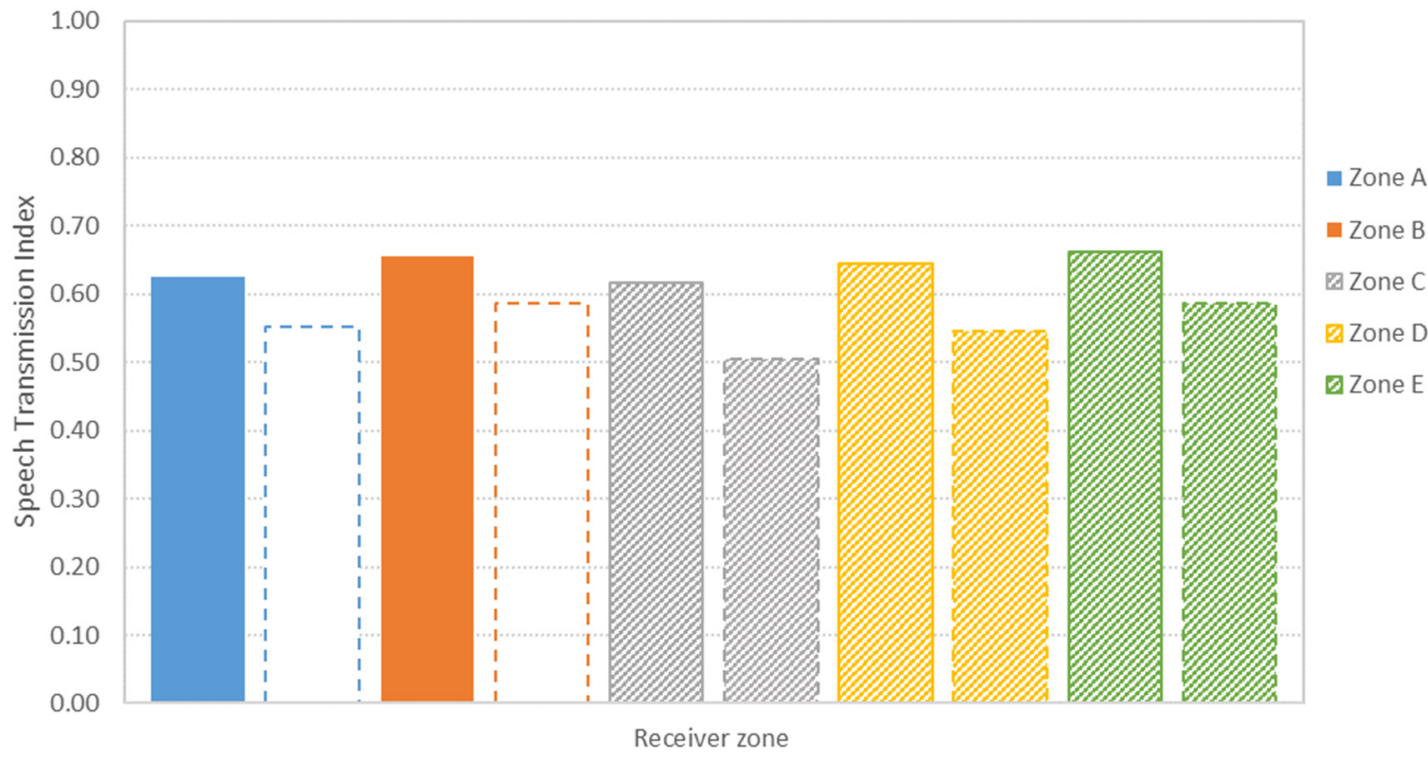

Figure 12. Speech transmission index (STI) obtained in the auditorium, when the variable acoustic solution provides maximum absorption (solid columns-configuration A) and when the variable acoustic solution provides maximum reflection (dashed columns-configuration R), by zones. 
Although STI is a parameter used to evaluate speech intelligibility, and therefore, important in the case of oratory/speech use, this value was also obtained for music configuration in order to evaluate its variation (see Figure 12). In the case of the selection of the reflective configuration (configuration R), the STI values varied between 0.51 and 0.59 , as shown in Figure 12. According to Table 6, this range is considered fair. When compared with the values obtained using the most absorbent configuration, there is an increase in this indicator of about $10 \%$.

\subsubsection{Concert Assessment}

\section{Reverberation Time}

As presented in Table 4, in the case of musical events, larger reverberation times are usually preferred, and thus, a more reflective configuration should be adopted. For the present case study, the auditorium should be configurated with the reflective surface facing the room (configuration $\mathrm{R}$ ), allowing to obtain an average reverberation time of $1.5 \mathrm{~s}$ (see Figure 7). With this value, it is possible to conclude that the recommended reverberation time proposed by Arau [33], for concerts, is accomplished. When using the reflective face with the minimum value stipulated by this author (according to Table 4), the requirement is met.

In the case of the reverberation time divided by zones (see Figure 13), it appears that only at $1000 \mathrm{~Hz}$ there is a slight change between the zones of the audience and the balcony, with the results being quite uniform in general. The average reverberation times, for the different zones, displays values varying between $1.5 \mathrm{~s}$ and $1.6 \mathrm{~s}$, resulting in a maximum difference of 1.3 JND, according to the reference provided in the ISO 3382-1 [35] (0.05\% for JND).

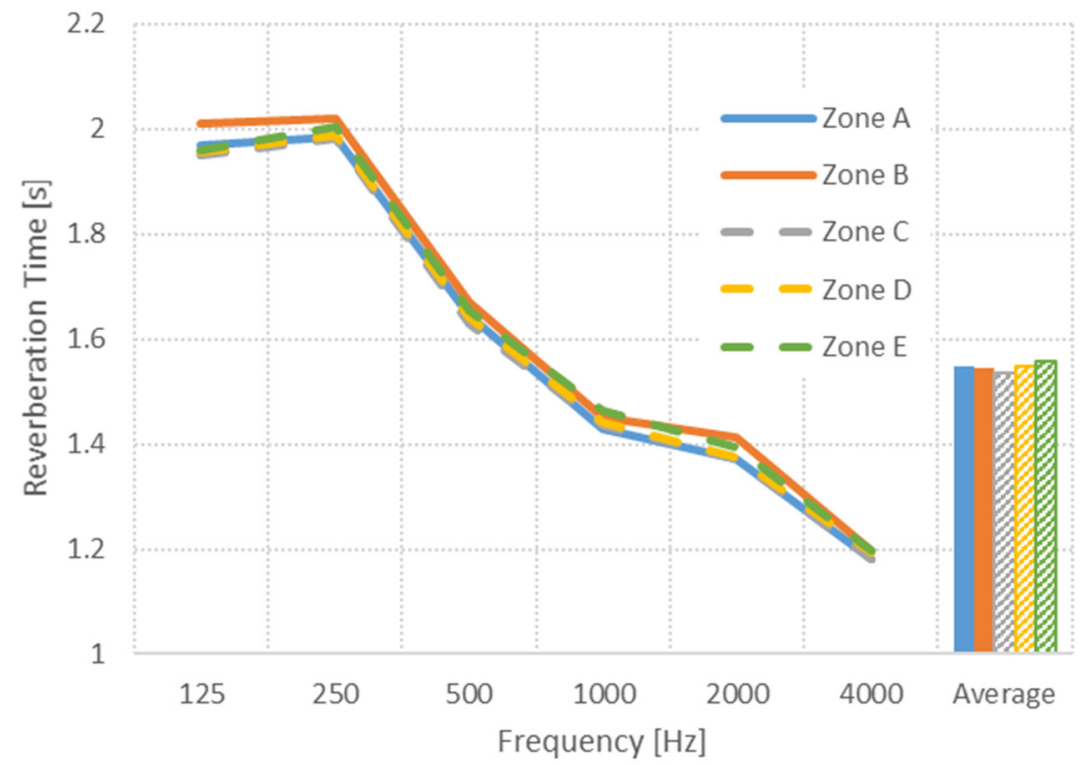

Figure 13. Reverberation time obtained in the auditorium, when the variable acoustic solution provides minimum absorption (configuration R), by zones.

At higher frequencies, the reverberation time of halls decreases due to air absorption. At lower frequencies, for speech or amplified music, a rise in the bass decreases intelligibility, so the reverberation should be kept constant with frequency. However, for music, a bass rise in reverberation time concerning the middle frequencies is considered desirable, allowing for a sensation of warmth [1]. An objective parameter to evaluate the warmth of a room is the bass ratio, which is expressed by $B R=\frac{R T_{125 \mathrm{~Hz}}+R T_{250 \mathrm{~Hz}}}{R T_{500 \mathrm{~Hz}}+R T_{1000 \mathrm{~Hz}}}$ [37]. This parameter was evaluated for the reflective configuration facing the room (see Figure 14); an average close to 1.30 , corresponding to a $30 \%$ rise in the lower frequencies concerning medium range frequencies, was obtained. 


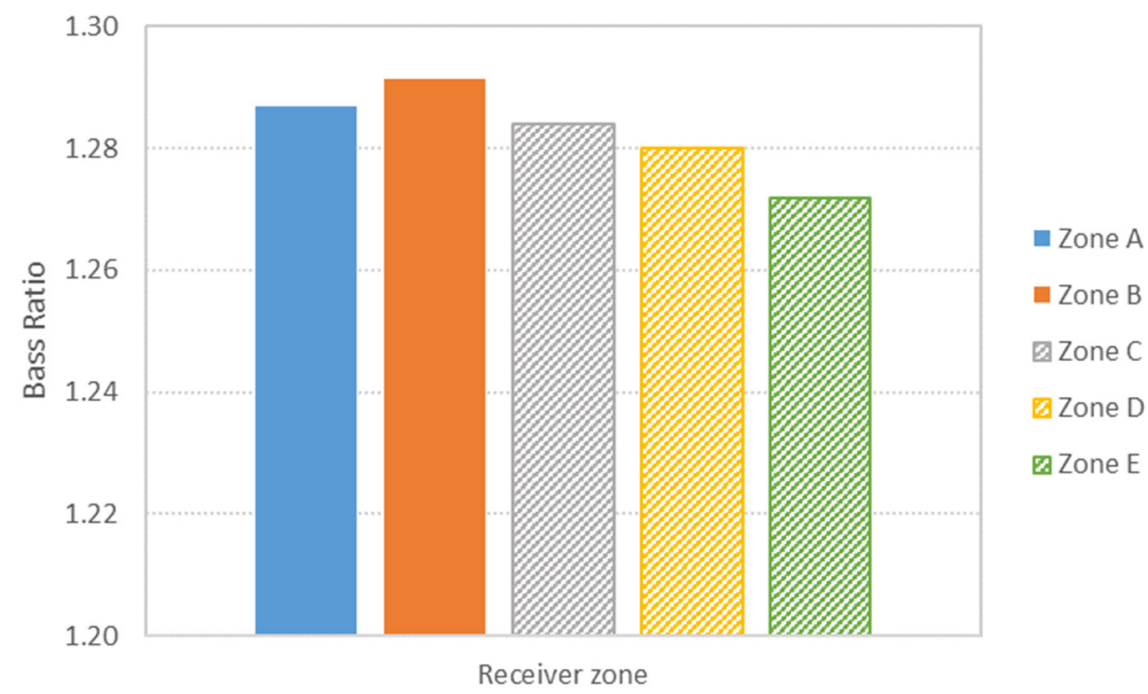

Figure 14. Bass ratio obtained in the auditorium, when the variable acoustic solution provides minimum absorption (configuration $\mathrm{R}$ ), by zones.

Early Decay Time (EDT)

The early decay time (EDT) is a parameter normally used to evaluate perceived reverberance. It is defined as the time corresponding to the first $10 \mathrm{~dB}$ fall of a decay curve, multiplied by a factor of 6 . If the reverberation curve is a straight line, the reverberation time and the EDT will be equal. In general, EDT and T60 values are very similar, but, in some cases, these values can be quite different and may indicate some unusual properties of the acoustics of the hall. The ratio EDT-RT proves to be an indication of diffuseness or directedness of the design. In a highly diffuse hall, the EDT/RT ratio tends to have a value close to 1 [1]. According to the standard ISO 3382-1, the average EDT should lie within $1 \mathrm{~s}$ and $3 \mathrm{~s}$. Figure 15 displays the EDT parameter by zones and also the ratio EDT-RT. Analysis of EDT values allows concluding that they lie within the range defined by ISO 3382-1. For the present performance space, it is possible to identify that ratio EDT/RT varies among zones, between 0.74 and 0.93 , being the lowest values situated in the zone below the balcony (zone B) and at the last places of the balcony (Zone E). In these zones of the audience area, lower ratios may result in less "live" music perception.

\section{Sound Pressure Level}

Figure 16 shows the equivalent sound pressure level at each receivers' position when the reflecting configuration (configuration $\mathrm{R}$ ) is used.

Table 7 shows the obtained variation of the sound pressure level $(\Delta \mathrm{L})$ in the case of music, at each receivers' line, concerning the position situated at one meter from the sound source. In the parterre zone, there is a small variation in the sound pressure level at the different receiver lines, and again the higher value is registered at $11.4 \mathrm{~m}$ away from the source, a region shadowed by the balcony. In general, the distribution of $\Delta \mathrm{L}$ values is quite uniform throughout the room, with a maximum difference of $2.8 \mathrm{~dB}$ among the several positions. 


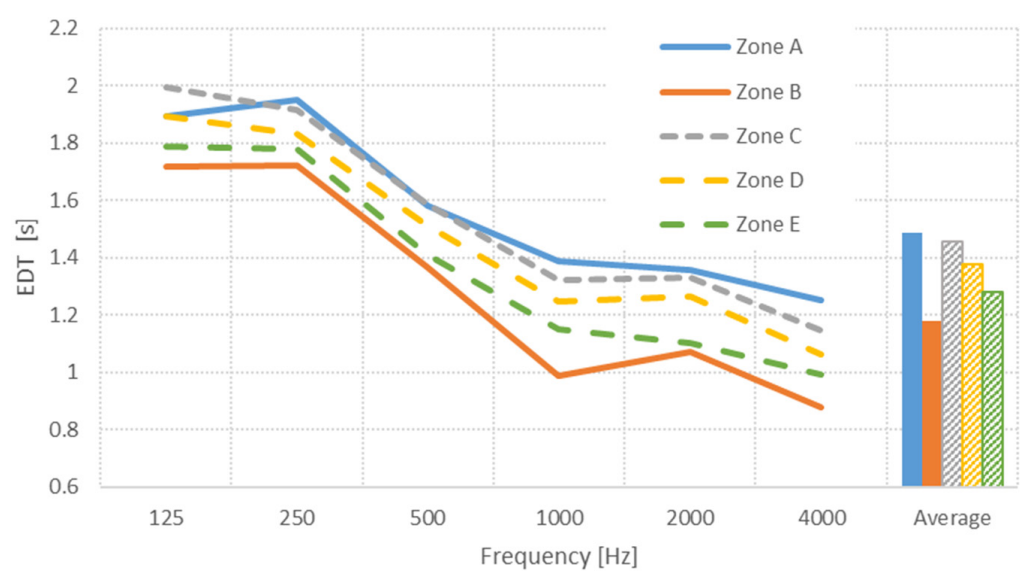

(a)

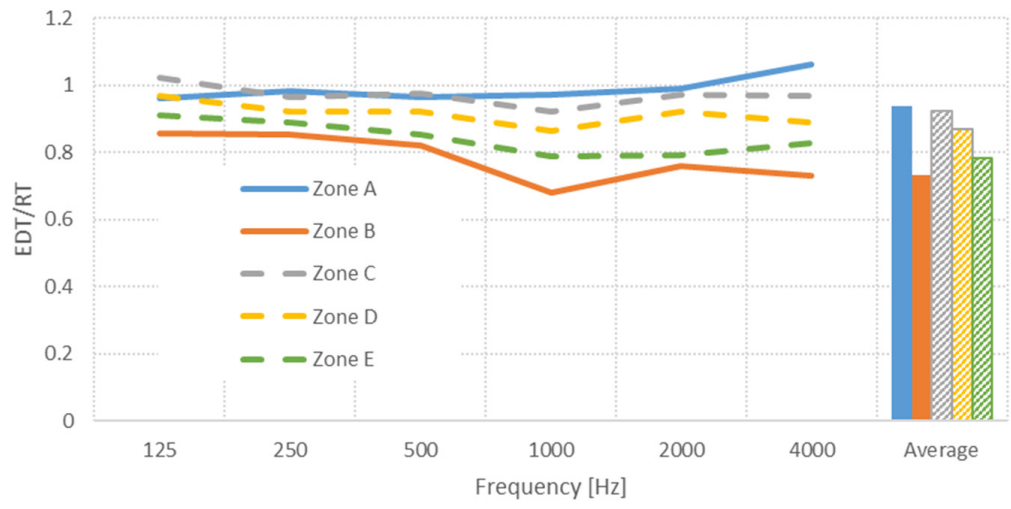

(b)

Figure 15. Early decay time (a) and relation RT/EDT (b) obtained in the auditorium, when the variable acoustic solution provides minimum absorption (configuration R), by zones.

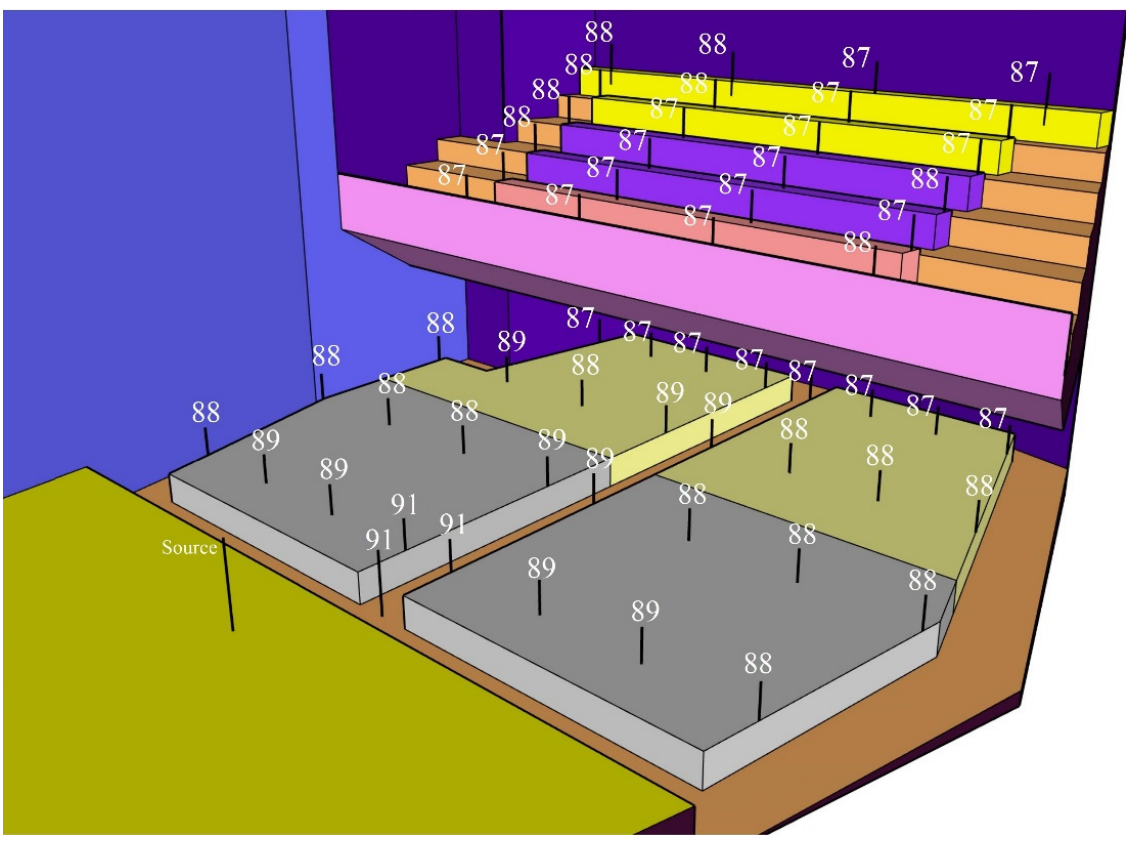

Figure 16. Map of the equivalent sound pressure levels, in $\mathrm{dB}$, for the variable acoustic configuration (configuration R) which provides minimum sound absorption (adequate for music use). 
Table 7. Differences between sound pressure levels registered close to the source, obtained at a receivers' line for music configuration use $(\Delta \mathrm{L})$.

\begin{tabular}{ccccccccccc}
\hline & \multicolumn{3}{c}{ Parterre } & \multicolumn{5}{c}{ Balcony } \\
\hline $\begin{array}{c}\text { Distance between receiver } \\
\text { reference receiver }(\mathrm{m})\end{array}$ & 2.9 & 5.2 & 8.2 & 11.4 & 8.1 & 9.2 & 10.2 & 11.4 & 12.5 & 13.3 \\
\hline$\Delta \mathrm{L}[\mathrm{dB}]$ & 1.8 & 3.2 & 3.2 & 4.6 & 4.1 & 4.2 & 4.0 & 3.9 & 3.9 & 3.9 \\
\hline
\end{tabular}

\section{Clarity (C80)}

The clarity (C80) is a parameter associated with the characterization of a given space for music. The calculation is performed, in a dB scale, as the logarithm of the energy contained in the first reflections in a time interval of $80 \mathrm{~ms}$ by the reverberant energy after $80 \mathrm{~ms}$, by the following equation [38]:

$$
\mathrm{C} 80=10 \log \frac{\int_{0}^{80 \mathrm{~ms}} p^{2}(t) d t}{\int_{80 \mathrm{~ms}}^{\infty} p^{2}(t) d t}
$$

According to Arau [33], a classification of values can be defined (see Table 8), which depends on the type of use of the indoor space.

Table 8. Recommended values of clarity (C80), suggested by Arau [33], depending on the type of use of the space.

\begin{tabular}{cc}
\hline Type of Use & Recommended Values \\
\hline Opera & $2 \mathrm{~dB}<\mathrm{C} 80<6 \mathrm{~dB}$ \\
\hline Concert & $-2 \mathrm{~dB}<\mathrm{C} 80<4 \mathrm{~dB}$ \\
\hline
\end{tabular}

Figure 17 shows the indicator $\mathrm{C} 80$, in octave frequency bands, by zones. It can be seen that, as the distance from the source increases, the curves also increase in amplitude. The average values in the frequency bands between $500 \mathrm{~Hz}$ and $2000 \mathrm{~Hz}$ (also displayed in Figure 17) vary between $1 \mathrm{~dB}$ and $4 \mathrm{~dB}$, complying with the recommended values proposed by Arau [33] for concerts.

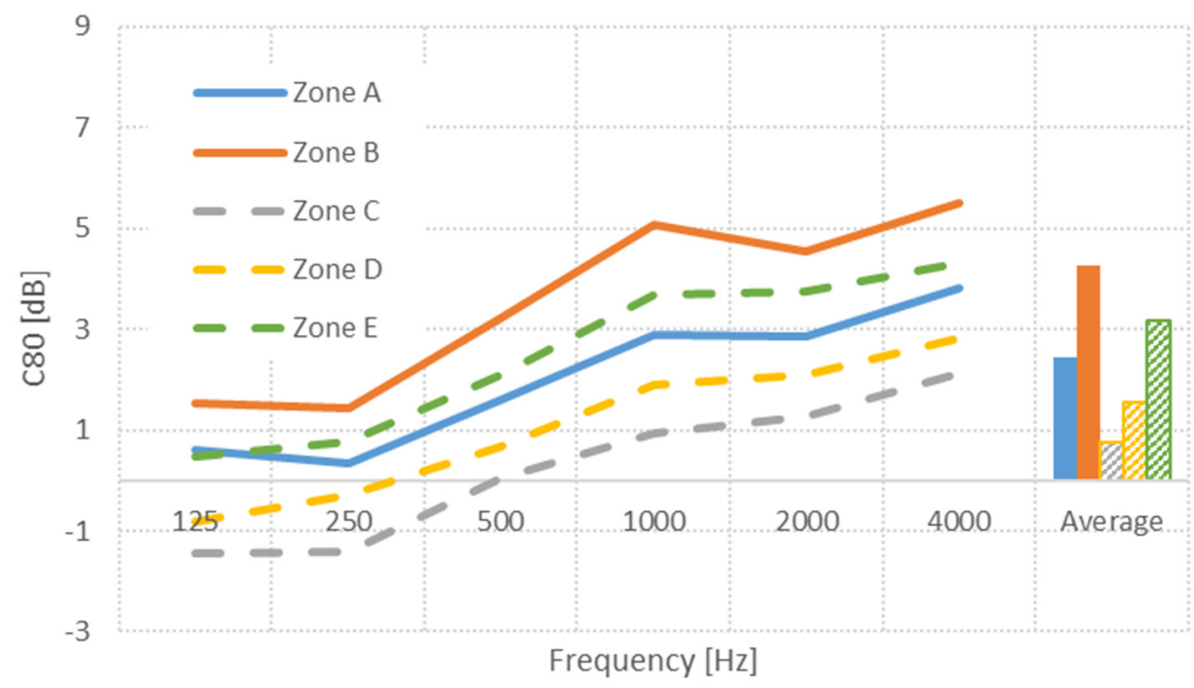

Figure 17. Clarity (C80) obtained in the auditorium, when the variable acoustic solution provides minimum absorption (configuration R), by zones. 
Strength $(\mathrm{G})$

The "amplification" of the sound by the room is described by the parameter strength (symbol G), in dB, and is defined in the ISO 3382-1 [35]; Equation (A7). The strength is the sound pressure level in the room relative to the sound pressure level in the free field at a distance of $10 \mathrm{~m}$ from the same source, which must be omnidirectional:

$$
\mathrm{G}=L_{p, \text { room }}-L_{p, \text { free field }}\left(\mathrm{r}_{0}=10 \mathrm{~m}\right)(\mathrm{dB})
$$

When the strength, $\mathrm{G}$, of a room is known, it is possible to estimate the sound pressure level at forte $(f)$ in the room when the emitted sound power at forte of the music ensemble, $L_{w}(f)$, is known, by using the following relation from ISO 3382-1 [35]:

$$
L_{p}(f)=L_{w}(f)+\mathrm{G}-31(\mathrm{~dB})
$$

The perceived acoustics of the room for music is characterized by the reverberation time (RT) and the strength (G) as a function of the space volume, and there is an optimal range for these values to have proper acoustics. If the reverberation time is too high, the sound would be too muddy, while if it is too low, it would be too dry. On the other hand, if the room has too high strength, the music will sound too loud and maybe quite annoying, while if the strength is too low, the music will sound weak and maybe disappointing to listen to [39].

According to the standard NS 8178 [34], the reference for the acoustic evaluation of a music room is the sound pressure level at forte, $L_{p}(f)$, within the range $85-90 \mathrm{~dB}$ for performance rooms. For a classical symphony orchestra playing at forte, the sound power level is around $110 \mathrm{~dB}$ at forte and around $120 \mathrm{~dB}$ at fortissimo. With these sound power levels, to obtain a sound pressure level at forte, a strength $(\mathrm{G})$ between $6 \mathrm{~dB}$ and $11 \mathrm{~dB}$ is required.

For the variable acoustic configuration $\mathrm{R}$, the values of $\mathrm{G}$ given by zones are shown in Figure 18, in octave bands and also after performing the average in the frequency bands of $500 \mathrm{~Hz}$ and $1000 \mathrm{~Hz}$. The average $\mathrm{G}$ varies between $9.4 \mathrm{~dB}$ and $10.4 \mathrm{~dB}$ among different zones. The major difference is equal to $1 \mathrm{JND}$, according to the reference provided in standard ISO 3382-1 [35] (for G, that standard indicates a JND of $1 \mathrm{~dB}$ ), meaning that there is a good distribution of this indicator within the auditorium. Analyzing the reference provided in the standard NS 8178 [34], we may conclude that the auditorium will provide good acoustics for loud music.

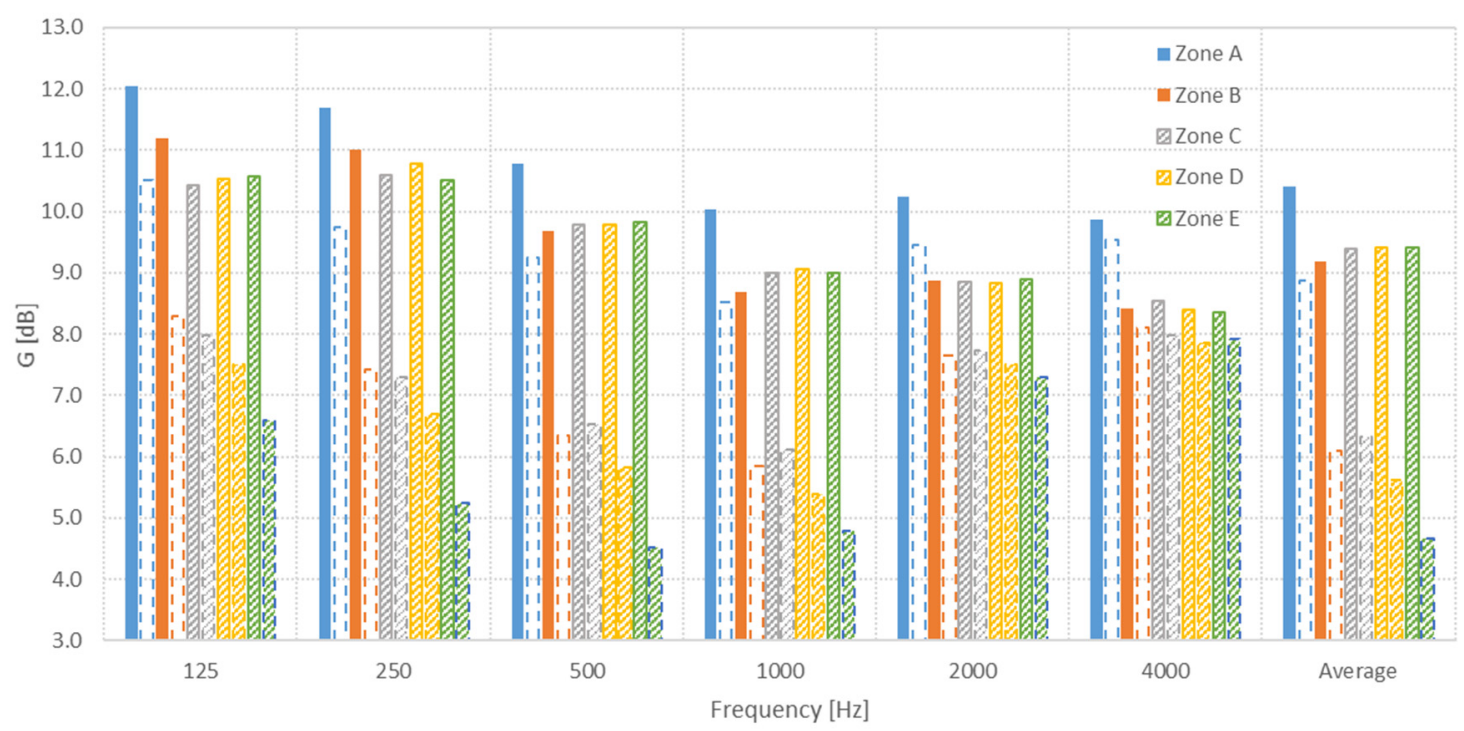

Figure 18. Strength parameter $(\mathrm{G})$ obtained in the auditorium, when variable acoustic solution provides maximum reflection (solid columns - configuration $\mathrm{R}$ ) and when the variable acoustic solution provides maximum absorption (dashed columns-configuration A) by zones. 
The strength provided by configuration A, which could be used for amplified music, was also computed and is also displayed in Figure 18 (dashed columns). Comparing the results provided by this configuration with the reflective one, the differences are very clear. In this case, the average result varies between $5 \mathrm{~dB}$ and $9 \mathrm{~dB}$, and the greater differences are found to be at seats near the stage, which are more influenced by direct sound. In this zone (zone A), the sound may appear too loud, compared to the other zones where the maximum differences are of $1 \mathrm{JND}$ and strength values decrease to $5 \mathrm{~dB}$ and $6 \mathrm{~dB}$.

\section{Early Lateral Energy Fraction (LF)}

The early lateral energy fraction (LF) is a parameter for the spatial impression of the room (a sense for the listener to be surrounded by the sound). A room is acoustically very spacious if it makes a sound source be perceived as being "wider". The LF is the linear ratio of sound, which arrives laterally to the ear in the time interval between $5 \mathrm{~ms}$ and $80 \mathrm{~ms}$, concerning the total sound from all directions, within the first $80 \mathrm{~ms}$. In other words, the LF shows the sense of sound spatiality. LF is generally measured from the impulse responses obtained using a "figure-of- 8 " microphone (to measure the lateral energy) in conjunction with an omnidirectional microphone (to measure the total energy) as follows [35]:

$$
L F=\frac{\int_{0.005}^{0.080} P_{L}{ }^{2}(t) d t}{\int_{0}^{0.080} p^{2}(t) d t}
$$

where $p_{L}^{2}(t)$ is the quadratic impulse response signal measured with a figure-of- $8 \mathrm{mi}-$ crophone, and $p^{2}(t)$ is the quadratic impulse response signal measured with an omnidirectional microphone, when the null of the figure-of- 8 microphone is pointed towards the source.

According to ISO 3382-1 [35], the recommended LF for music venues varies between $5 \%$ and $35 \%$. A too high proportion of lateral sound can be disturbing since it compromises identification with the performers. The average value of LF is obtained from frequencies between $125 \mathrm{~Hz}$ and $1000 \mathrm{~Hz}$. This parameter is displayed below (Figure 19) for configuration $R$. For the present case study, this value varies between 0.19 and 0.32 , which falls within the recommended range.

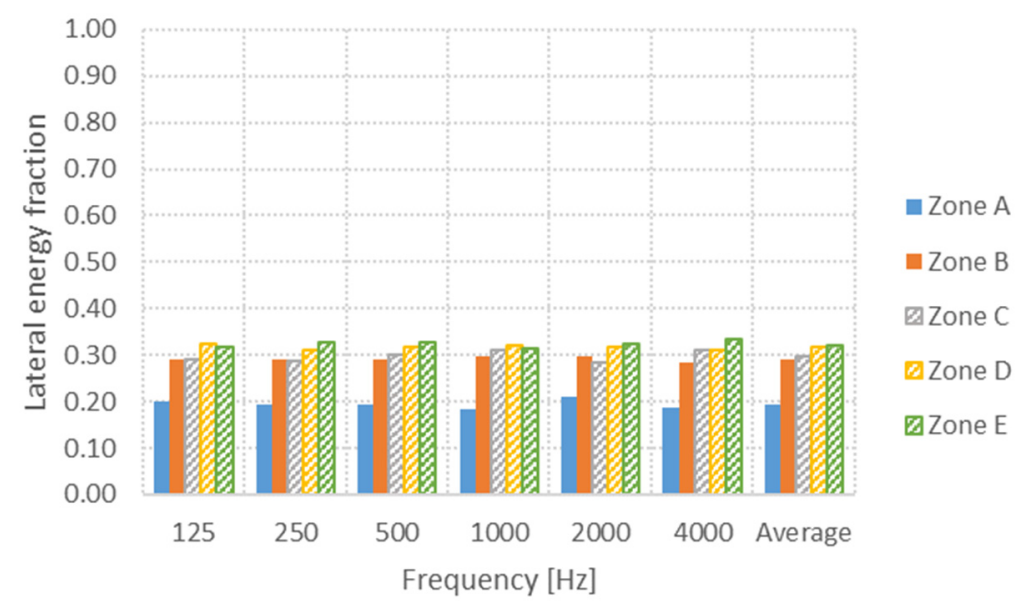

Figure 19. Early lateral energy fraction (LF) obtained in the auditorium, when the variable acoustic solution provides minimum absorption (configuration R), by zones.

The major difference among zones is higher than 1 JND, but less than 3 JND according to the reference provided in standard ISO 3382-1 (for LF, the standard indicates a JND of $0.05)$, meaning that, except for zone A (near the stage), where the sound from source may be more prominent, in general, there is a good distribution of this indicator within the auditorium and the sound will be perceived as "wider". 


\subsection{Summary of the Results}

In this section, a summary of the results for the analyzed configurations is provided so as to give an overall perception of the sound quality that can be accomplished in the auditorium with the variable acoustics solution. Table 9 displays the single number acoustic indicators obtained when the configuration for maximum absorption is used. It is possible to conclude that, for uses such as speech or amplified music, the required sound quality is achieved. A good spatial distribution of these indicators is also guaranteed for these types of use (see Table 10).

Table 9. Single number acoustic indicators for the auditorium with configuration A.

\begin{tabular}{ccccc}
\hline $\begin{array}{c}\text { Single Number } \\
\text { Acoustic Indicator }\end{array}$ & Configuration A & Requirement & $\begin{array}{c}\text { Requirement } \\
\text { Accomplished }\end{array}$ & $\begin{array}{c}\text { Single Number } \\
\text { Frequency Averaging [Hz] }\end{array}$ \\
\hline T30 (s) & {$[0.9 \mathrm{~s} ; 1 \mathrm{~s}]$} & $\leq 0.9 \mathrm{~s}$ & $\checkmark$ & $500 \mathrm{and} 1000 \mathrm{~Hz}$ \\
\hline D50 (\%) & {$[70 \% ; 71 \%]$} & $>50 \%$ & $\checkmark$ & $500 \mathrm{and} 1000 \mathrm{~Hz}$ \\
\hline STI (\%) & {$[62 \% ; 66 \%]$} & $\begin{array}{c}{[60 ; 75 \%]} \\
\text { Good }\end{array}$ & +- & Overall sound pressure \\
level
\end{tabular}

$\checkmark$-Required sound quality is achieved; + - Considered acceptable.

Table 10. Spatial distribution of acoustic indicators for configuration A.

\begin{tabular}{cccccc}
\hline \multirow{2}{*}{ Single Number Acoustic Indicator } & \multicolumn{2}{c}{ Parterre } & \multicolumn{3}{c}{ Balcony } \\
\cline { 2 - 6 } & Zone A & Zone B & Zone C & Zone D & Zone E \\
\hline T30 (s) & 0.93 & 0.93 & 0.96 & 0.93 & 0.93 \\
\hline D50 (\%) & 70 & 71 & 71 & 70 & 70 \\
\hline STI (\%) & 63 & 65 & 62 & 64 & 66 \\
\hline SPL [dB] & 87.4 & 85.6 & 85.0 & 84.9 & 84.2 \\
\hline
\end{tabular}

When the configuration providing maximum reverberation of the space is applied, most of the analyzed acoustic indicators (see Table 11) fall into the acoustic requirements for acoustic loud music. Regarding the spatial distribution of the indicators (see Table 12), the JND calculated, taking into account the minimum value obtained in a zone of the auditorium, indicates values for the parameters that do not exceed $4 \mathrm{JND}$.

Table 11. Single number acoustic indicators for the auditorium for configuration $\mathrm{R}$.

\begin{tabular}{cccc}
\hline \multirow{2}{*}{ Acoustic Indicator } & Auditorium & \multicolumn{2}{c}{ Acoustic Requirement Evaluation } \\
\cline { 2 - 4 } & Configuration $\mathbf{R}$ & Requirement & $\begin{array}{c}\text { Requirement } \\
\text { Accomplished }\end{array}$ \\
\hline T30 $(\mathrm{s})$ & {$[1.5 \mathrm{~s} ; 1.6 \mathrm{~s}]$} & {$[1.5 \mathrm{~s} ; 1.8 \mathrm{~s}]$} & $\checkmark$ \\
\hline BR & {$[1.27 ; 1.29]$} & $\begin{array}{c}\text { Around } 1.3 \text { is } \\
\text { considered acceptable }\end{array}$ & +- \\
\hline EDT $(\mathrm{s})$ & {$[1.2 \mathrm{~s}-1.5 \mathrm{~s}]$} & {$[1 \mathrm{~s} ; 3 \mathrm{~s}]$} & $\checkmark$ \\
\hline RT $/ \mathrm{EDT}$ & {$[0.73 ; 0.94]$} & $\begin{array}{c}\text { EDT } / \text { RT ratio should } \\
\text { have a value close to } 1\end{array}$ & +- \\
\hline C80 $(\mathrm{dB})$ & {$[1 \mathrm{~dB}-4 \mathrm{~dB}]$} & {$[-2 \mathrm{~dB} ; 4 \mathrm{~dB}]$} & $\checkmark$ \\
\hline $\mathrm{G}(\mathrm{dB})$ & {$[9.2 \mathrm{~dB}-10.4 \mathrm{~dB}]$} & {$[6 \mathrm{~dB} ; 11 \mathrm{~dB}]$} & $\checkmark$ \\
\hline $\mathrm{LF}$ & {$[0.19 ; 0.32]$} & {$[0.05 ; 0.35]$} & $\checkmark$ \\
\hline Max $\Delta \mathrm{L}[\mathrm{dB}]$ & $1.4 \mathrm{~dB}$ & $\leq 1 \mathrm{~dB}$ & $\checkmark$ \\
\hline
\end{tabular}

$\checkmark$-Required sound quality is achieved; + - Considered acceptable. 
Table 12. Spatial distribution of acoustic indicators and JND values for configuration R.

\begin{tabular}{|c|c|c|c|c|c|c|c|c|c|}
\hline \multirow[b]{2}{*}{$\begin{array}{c}\text { Subjective } \\
\text { Listener Aspect }\end{array}$} & \multirow[b]{2}{*}{$\begin{array}{l}\text { Single Number } \\
\text { Acoustic } \\
\text { Indicator }\end{array}$} & \multicolumn{2}{|c|}{ Parterre } & \multicolumn{3}{|c|}{ Balcony } & \multicolumn{3}{|c|}{ Spatial Distribution Evaluation } \\
\hline & & Zone A & Zone B & Zone C & Zone D & Zone E & $\begin{array}{c}\text { Just Noticeable } \\
\text { Difference among } \\
\text { Zones (JND) }\end{array}$ & $\begin{array}{c}\text { Reference Just } \\
\text { Noticeable } \\
\text { Difference (JND) }\end{array}$ & Analysis \\
\hline- & $\mathrm{T} 30(\mathrm{~s})$ & 1.55 & 1.55 & 1.54 & 1.55 & 1.56 & - & - & - \\
\hline- & BR & 1.29 & 1.29 & 1.28 & 1.28 & 1.27 & - & - & - \\
\hline $\begin{array}{l}\text { Perceived } \\
\text { reverberance }\end{array}$ & EDT (s) & 1.49 & 1.18 & 1.46 & 1.38 & 1.28 & $\leq 4 \mathrm{JND}$ & $5 \%$ & $\begin{array}{l}\text { Differences in the } \\
\text { perception will } \\
\text { be noticed bellow } \\
\text { the balcony }\end{array}$ \\
\hline- & RT/EDT & 0.94 & 0.73 & 0.92 & 0.87 & 0.78 & - & - & - \\
\hline $\begin{array}{l}\text { Perceived clarity } \\
\text { of sound }\end{array}$ & $\mathrm{C} 80(\mathrm{~dB})$ & 2.4 & 4.3 & 0.8 & 1.6 & 3.2 & $\leq 4 \mathrm{JND}$ & $1 \mathrm{~dB}$ & $\begin{array}{l}\text { Differences in the } \\
\text { perception of } \\
\text { clarity may be } \\
\text { noticed }\end{array}$ \\
\hline $\begin{array}{l}\text { Subjective level } \\
\text { of sound }\end{array}$ & $\mathrm{G}(\mathrm{dB})$ & 10.4 & 9.2 & 9.4 & 9.4 & 9.4 & $1 \mathrm{JND}$ & $1 \mathrm{~dB}$ & $\checkmark$ \\
\hline $\begin{array}{l}\text { Apparent } \\
\text { source width }\end{array}$ & LF & 0.19 & 0.29 & 0.30 & 0.32 & 0.32 & $\leq 3 \mathrm{JND}$ & 0.05 & $\begin{array}{l}\text { Differences in the } \\
\text { perception of } \\
\text { source will be } \\
\text { noticed in the } \\
\text { front seats }\end{array}$ \\
\hline - & SPL [dB] & 88.7 & 87.7 & 87.2 & 87.3 & 87.4 & - & - & - \\
\hline
\end{tabular}

It should be mentioned that the results presented in this paper are intended to demonstrate the usefulness of the proposed variable acoustics solution, and its potential for practical use in realistic scenarios. Indeed, the presented conceptual system can be adapted for other specific panel configurations and using different air gap dimensions, thus leading to a very flexible conceptual solution that may be tailored for each specific application. Furthermore, due to its internal structure, intermediate configurations may allow fine tuning the solution after application, based on measurements and on the specific requirements of each project.

\section{Conclusions}

In this paper, a variable acoustic solution, based on the use of perforated panel systems that may be suitable to adapt the auditorium acoustic conditions to different types of use, was addressed. While its surface appearance is kept constant, the acoustic properties may vary by either closing the holes of the perforated panel or changing the position of a porous material embedded inside the air gap. Sound absorption provided by possible configurations was calculated, using an analytical approach based on the Transfer Matrix Method (TMM). This analytical model was tested for the concept herein proposed, and a good agreement with the experimental results was attained. Ray tracing simulations of an auditorium were then employed to analyze the different possibilities in terms of the room acoustic behavior. Configurations providing maximum absorption and minimum absorption of the proposed concept solution were discussed in detail through the evaluation of important acoustic indicators for each type of use and allowed for the conclusion that sound quality may be achieved for types of use, such as speech, amplified music or acoustic ensemble music. It was also interesting to note that a good spatial distribution of the calculated parameters was obtained for the configuration related with speech use. Regarding music configuration, in general, the indicators display also good spatial distribution, although differences in some indicators were found, mainly below the balcony where fewer early reflections reach this zone. The spatial impression of the room is also perceived as being "wider" in the back seats than in the front seats, where sound energy that reaches this zone is mainly that from the stage.

For further research, the automation of the proposed solution will be addressed through the use of electromechanical systems, as well as the control system that will allow each panel to be controlled remotely and independently. 
Author Contributions: Funding acquisition, L.G.; investigation, D.M., A.G., J.R. and P.P.; methodology, A.P., L.G., D.M. and J.C.; resources, L.G.; supervision, A.P., L.G. and J.R.; visualization, A.G. and D.M.; writing-original draft, A.P., A.G., J.C. and P.P.; writing-review and editing, A.P., L.G. and P.A.M. All authors have read and agreed to the published version of the manuscript.

Funding: This work is financed by FEDER funds through the Competitivity Factors Operational Programme-COMPETE within the scope of the project ADJUST-Development of acoustic panels progressively adjustable with smart acting-SII \& DT Project CENTRO-01-0247-FEDER-033884. This work was partly financed by FCT/MCTES through national funds (PIDDAC) under the R\&D Unit Institute for Sustainability and Innovation in Structural Engineering (ISISE), under reference UIDB/04029/2020 and by Regional Operational Programme CENTRO2020 within the scope of project CENTRO-01-0145-FEDER-000006 (SUSpENsE).

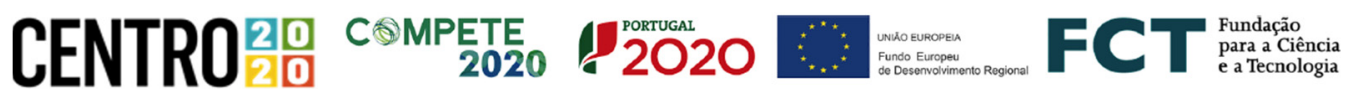

Institutional Review Board Statement: Not applicable.

Informed Consent Statement: Not applicable.

Data Availability Statement: Data available on request due to restrictions, e.g., privacy or ethical. The data presented in this study are available on request from the corresponding author.

Conflicts of Interest: The authors declare no conflict of interest.

\section{References}

1. Barron, M. Acoustics for multi-purpose use. In Auditorium Acoustics and Architectural Design, 2nd ed.; Spon Press: London, UK; New York, NY, USA, 2010; pp. 385-408.

2. Poletti, M.A. Active acoustic systems for the control of room acoustics. Build. Acoust. 2011, 18, 237-258. [CrossRef]

3. Thün, G.; Velikov, K.; Sauvé, L.; McGee, W. Design Ecologies for Responsive Environments: Resonant Chamber, an Acoustically Performative System; ACADIA 12; Synthetic Digital Ecologies: San Francisco, CA, USA, 2012.

4. Everest, F.A.; Pohlmann, K.C. Adjustable Acoustics. In Master Handbook of Acoustics, 6th ed.; McGraw-Hills: New York, NY, USA, 2009; pp. 375-390.

5. Cairoli, M. Architectural customized design for variable acoustics in a multipurpose auditorium. Appl. Acoust. 2018, 140, 167-177. [CrossRef]

6. $\quad$ Egan, M.D. Architectural Acoustics; J. Ross Publishing: Plantation, FL, USA, 2007; pp. 134-142.

7. Beranek, L. Concert Halls and Opera Houses: Music, Acoustics, and Architecture, 2nd ed.; Springer: New York, NY, USA, 2004; pp. 549-550.

8. Long, M. Architectural Acoustics; Elsevier Academic Press: Burlington, MA, USA, 2006; pp. 579, $653-657$.

9. Sadeghnia, G.R. Data-driven IoT-platform for optimizing variable acoustics in multifunctional performance spaces. J. Acoust. Soc. Am. 2019, 146, 2851. [CrossRef]

10. Adelman-Larsen, N.W.; Thompson, E.R.; Gade, A.C. Suitable reverberation times for halls for rock and pop music. J. Acoust. Soc. Am. 2010, 127, 247-255. [CrossRef] [PubMed]

11. Adelman-Larsen, N.W. Rock and Pop Venues: Acoustic and Architectural Design; Springer: Berlin/Heidelberg, Germany, 2014; pp. 140-142.

12. Kusaka, M.; Sakagami, K.; Okuzono, T.; Kido, S.; Yamaguchi, D. Three-dimensional MPP space absorbers: An overview of the project and recent development. In Proceedings of the Inter-Noise and Noise-Con Congress and Conference Proceedings, Seoul, Korea, 23-26 August 2020; Volume 261, pp. 358-368.

13. Sakagami, K.; Kusaka, M.; Okuzono, T.; Kido, S.; Yamaguchi, D. Diffuse-field sound absorption characteristics of a sphericalmicroperforated space absorber. Acoust. Sci. Technol. 2020, 41, 784-787. [CrossRef]

14. Cox, T.; d'Antonio, P. Acoustic Absorbers and Diffusers: Theory, Design and Application, 3rd ed.; CRC Press: Boca Raton, FL, USA, 2017; pp. 225-255.

15. Vorländer, M. Auralization: Fundamentals of Acoustics, Modelling, Simulation, Algorithms and Acoustic Virtual Reality; Springer: Berlin/Heidelberg, Germany, 2008; pp. 181-196.

16. Lo Turco, M.; Zich, U.; Astolfi, A.; Shtrepi, L.; Poaola, B.M. From digital design to physical model. Origami techniques applied to dynamic panelling shapes for acoustic performance control. In Proceedings of the 35th International Conference on Education and Research in Computer Aided Architectural Design in Europe, Rome, Italy, 20-22 September 2017.

17. Pellegrino, S. Deployable Structure; Springer: Vienna, Austria, 2001.

18. Kolarevic, B.; Peters, B.; Peters, T. Parametric Evolution, Inside Smart Geometry: Expanding the Architectural Possibilities of Computational Design; Wiley \& Sons: New York, NY, USA, 2013. 
19. Panneton, R. Comments on the limp frame equivalent fluid model for porous media. J. Acoust. Soc. Am. 2007, 122, EL217-EL222. [CrossRef] [PubMed]

20. Bonfiglio, P.; Pompoli, F. Inversion problems for determining physical parameters of porous materials: Overview and comparison between different methods. Acta Acust. United Acust. 2013, 99, 341-351. [CrossRef]

21. Ramis, J.; Del Rey, R.; Alba, J.; Godinho, L.; Carbajo, J. A model for acoustic absorbent materials derived from coconut fiber. Mater. Construcción 2014, 64, e008. [CrossRef]

22. Crandall, I.B. Theory of Vibrating Systems and Sound; Van Nostrand: New York, NY, USA, 1926.

23. Patraquim, R.; Godinho, L.; Tadeu, A.; Amado-Mendes, P. Influence of the Presence of Lining Materials in the Acoustic Behaviour of Perforated Panel Systems; ICSV 18: Rio de Janeiro, Brazil, 2018.

24. Mechel, F.P. Formulas of Acoustics, 2nd ed.; Springer: Berlin/Heidelberg, Germany, 2008; p. 796.

25. Wu, M. Micro-Perforated Panels Duct Silencing. Noise Control Eng. J. 1997, 45, 69-77. [CrossRef]

26. ISO 10534-2. Acoustics: Determination of Sound Absorption Coefficient and Impedance in Impedances Tubes. Part 2: Transfer-Function Method; International Standards Organization: Geneva, Switzerland, 1998.

27. Larner, D.; Davy, J. The prediction of the diffuse field sound absorption of perforated panel systems. In Proceedings of the 44th InterNoise Congress and Exposition on Noise Control Engineering, San Francisco, CA, USA, 9-12 August 2015.

28. Rindel, J.H. The use of computer modelling in room acoustics. J. Vibroeng. 2000, 3, $219-224$.

29. Dance, S.M.; Van Buuren, G. Effects of damping on the low-frequency acoustics of listening rooms based on an analytical model. J. Sound Vib. 2013, 332, 6891-6904. [CrossRef]

30. Isbert, A.C. Diseño Acústico de Espacios Arquitectónicos; Universidad Politécnica de Catalunya: Catalonia, Spain, 1998; pp. 34-35, 184.

31. Celenit Technical Guide. Available online: https://www.celenit.com/Public/Downloads.php?celenit_depliant_ad_manuale_itpdf.pdf\&Open (accessed on 20 January 2021).

32. Decree-Law, n. ${ }^{\circ}$ 96/2008, June 9th, Regulamento dos Requisitos Acústicos dos Edifícios (RRAE). Available online: http:/ / www. oern.pt/documentos/legislacao/d_dl_dr/DL96_2008.pdf (accessed on 10 January 2021). (In Portuguese)

33. Arau, H. ABC de la Acústica Arquitectónica; CEAC: Barcelona, Spain, 1999; pp. 217-288.

34. NS 8178:2014. Acoustic Criteria for Rooms and Spaces for Music Rehearsal and Performance; Standard Norge: Oslo, Norway, 2014. (In Norwegian)

35. ISO 3382-1:2009. Acoustics—Measurement of Room Acoustic Parameters_Part 1: Performance Spaces; International Organization for Standardization: Brussels, Belgium, 2009.

36. Rossing, T. Handbook of Acoustics; Springer Science \& Business Media: New York, NY, USA, 2007; pp. 437-438.

37. Beranek, L.L. Concert Halls and Opera Houses: How They Sound; Springer: New York, NY, USA, 1996.

38. Reichardt, W.; Alim, O.A.; Schmidt, W. Definition and basis of making an objective evaluation to distinguish between useful and useless clarity defining musical performances. Acta Acust. United Acust. 1975, 32, 126-137.

39. Rindel, J.H. Rooms for Music-Acoustical Needs and Requirements; Baltic-Nordic Acoustic Meeting: Tallinn, Estonia, 2014. 